\title{
A Graph Calculus for Predicate Logic ${ }^{*}$
}

\author{
Paulo A. S. Veloso \\ COPPE-UFRJ \\ Systems and Computer Engin. Program \\ UFRJ: Federal University of Rio de Janeiro \\ RJ, Brazil \\ pasveloso@gmail.com
}

\author{
Sheila R. M. Veloso \\ FEN-UERJ \\ Systems and Computer Engin. Dept., Fac. of Engineering \\ UERJ: State University of Rio de Janeiro \\ RJ , Brazil \\ sheila.murgel.bridgedgmail.com
}

\begin{abstract}
We introduce a refutation graph calculus for classical first-order predicate logic, which is an extension of previous ones for binary relations. One reduces logical consequence to establishing that a constructed graph has empty extension, i. e. it represents $\perp$. Our calculus establishes that a graph has empty extension by converting it to a normal form, which is expanded to other graphs until we can recognize conflicting situations (equivalent to a formula and its negation).
\end{abstract}

\section{Introduction}

We present a refutation graph calculus for classical first-order predicate logic. This approach is based on reducing logical consequence to showing that a constructed graph has empty extension, representing the logical constant $\perp$. Our sound and complete calculus establishes when a graph has empty extension.

For instance, given formulas $\psi, \theta$ and $\varphi$, to establish that $\varphi$ follows from $\{\psi, \theta\}$, we construct a graph $\mathrm{G}$ corresponding to $\{\psi, \theta\} \cup\{\neg \varphi\}$ and show that $\mathrm{G}$ has empty extension. Now, our calculus establishes that a graph has empty extension by converting it to a normal form, which is expanded to other graphs until we can recognize conflicting situations (equivalent to a formula and its negation).

Formulas are often written down on a single line [3]. Graph calculi rely on two-dimensional representations providing better visualization [2] 1 In the realm of binary relations, a simple calculus (with linear derivations) [2, 3] was extended for handling complement: direct calculi [5, 7] and refutation calculi [13]. Our new calculus is a further extension, inheriting much of the earlier terminology (such as 'graph', 'slice' and 'arc'), together with some ideas from Peirce's diagrams for relations [11, 4]. The present calculus involves two new aspects: extension to arbitrary predicates (which affects the representation) and allowing formulas within the graphs.

The structure of this paper is as follows. Section 2 motivates the underlying ideas with some illustrative examples. Section 3 introduces our graph language: syntax, semantics and some constructions. In Section 4 we introduce our graph calculus: its rules and goal. Section 5 presents some concluding remarks, including comparison with related works.

\section{Motivation}

We begin by motivating our ideas with some illustrative examples.

${ }^{*}$ Research partly sponsored by the Brazilian agencies CNPq and FAPERJ.

${ }^{1}$ The structure of $(x+y) \cdot(z \div w)$ is more apparent in the notation $\left(\begin{array}{c}x \\ + \\ y\end{array}\right) \cdot\left(\begin{array}{c}z \\ \div \\ w\end{array}\right)$ (see also [1]).

D. Kesner and P. Viana (Eds.): LSFA 2012

EPTCS 113, 2013, pp. 153-168 doi 10.4204/EPTCS.113.15 (c) Veloso \& Veloso

This work is licensed under the Creative Commons Attribution License. 
We know that consequence can be reduced to unsatisfiability. We will indicate how one can represent formulas graphically and then establish consequence by graphical means.

First, we indicate how we can represent (some) formulas graphically (see 3.1 for more details).

We represent an atomic formula by arrows to predicate symbols coming from its arguments. So, we represent the formulas $\mathrm{p}(\mathrm{u})$ and $\mathrm{r}(\mathrm{u}, \mathrm{v})$, respectively, as follows:
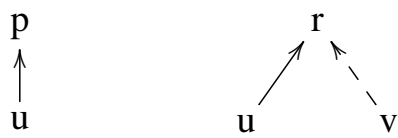

The former illustrates a 1-ary arc. The latter is an example of a 2-ary arc, which will be satisfied by the choices of values $a$ and $b$ for $\mathrm{u}$ and $\mathrm{v}$, respectively, with the pair $(a, b)$ in the 2-ary relation interpreting $\mathrm{r}$.

We obtain a representation for a conjunction by joining those of its formulas. So, we represent the formula $\mathrm{p}(\mathrm{u}) \wedge \mathrm{r}(\mathrm{u}, \mathrm{v})$ as follows:

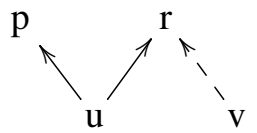

This set of 2 arcs is an example of a draft, which also represents the set $\{p(u), r(u, v)\}$. This draft $D$ will be satisfied exactly by the assignments satisfying both $\mathrm{p}(\mathrm{u})$ and $\mathrm{r}(\mathrm{u}, \mathrm{v})$.

To represent an existential quantification, we hide the node corresponding to the quantified variable, leaving only the rest visible. For instance, from formula $\mathrm{p}(\mathrm{u}) \wedge \mathrm{r}(\mathrm{u}, \mathrm{v})$, we obtain $\exists \mathrm{x}(\mathrm{p}(\mathrm{x}) \wedge \mathrm{r}(\mathrm{x}, \mathrm{v}))$. We can use the representation of the former to represent the latter: we place the above draft $D$ within a box and mark $\mathrm{v}$ as visible, which we represent as follows:

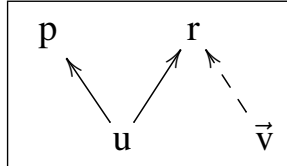

This is an example of a 1-ary slice. The interpretation of this slice $S$ is the 1-ary relation consisting of the values $b$ such that, for some $a$, the assignment $\mathrm{u} \mapsto a, \mathrm{v} \mapsto b$ satisfies the underlying draft $\mathrm{D}$.

Now, we can represent formula $\neg \exists \mathrm{x}(\mathrm{p}(\mathrm{x}) \wedge \mathrm{r}(\mathrm{x}, \mathrm{v}))$ by complementing this slice $S$. As - stands for complement, we represent $\neg \exists \mathrm{x}(\mathrm{p}(\mathrm{x}) \wedge \mathrm{r}(\mathrm{x}, \mathrm{v}))$ as follows:

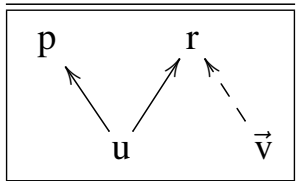

A draft consists of finite sets of names and of arcs (giving constraints on the names). A slice consists of a draft and a list of distinguished names, which we indicate by special marks, such as ' $\rightarrow$ '.

Next, we illustrate how one can establish consequence by graphical means. The idea is reducing unsatisfiability of a (finite) set of formulas to that of its corresponding draft.

We begin with an example that is basically propositional. Then, we examine other examples with equality $\doteq$ and existential quantifiers (see 3.2 and 4.1 for more details).

Example 2.1. Consider $\mathrm{p}(\mathrm{u}) \wedge \mathrm{q}(\mathrm{u}) \models \mathrm{p}(\mathrm{u})$. As mentioned, we reduce it to $\{\mathrm{p}(\mathrm{u}) \wedge \mathrm{q}(\mathrm{u}), \neg \mathrm{p}(\mathrm{u})\} \models \perp$. We can represent the formulas by (sets of) arcs as follows: 
Veloso \& Veloso

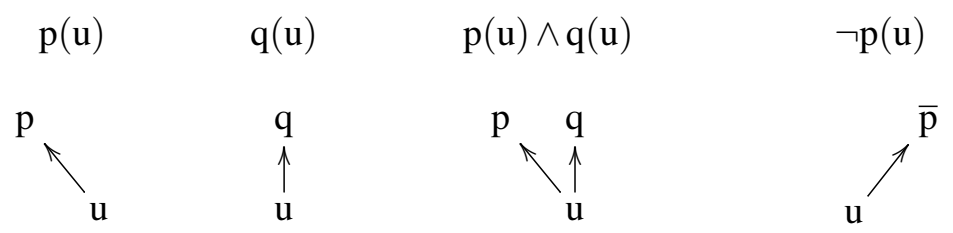

We can obtain a representation for the set $\{\mathrm{p}(\mathrm{u}) \wedge \mathrm{q}(\mathrm{u}), \neg \mathrm{p}(\mathrm{u})\}$ by joining those of its formulas:

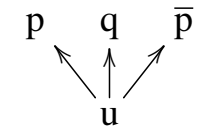

Within this draft for $\{\mathrm{p}(\mathrm{u}) \wedge \mathrm{q}(\mathrm{u}), \neg \mathrm{p}(\mathrm{u})\}$, we find the conflicting situation (as ${ }^{-}$stands for complement):

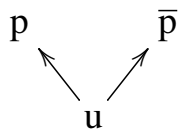

Thus, the representation of $\{\mathrm{p}(\mathrm{u}) \wedge \mathrm{q}(\mathrm{u}), \neg \mathrm{p}(\mathrm{u})\}$ is unsatisfiable.

Example 2.2. We know that $\mathrm{p}(\mathrm{u}) \not \models \mathrm{p}(\mathrm{v})$, i. e. $\{\mathrm{p}(\mathrm{u}), \neg \mathrm{p}(\mathrm{v})\} \not \models \perp$. The corresponding draft is:

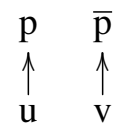

Here, we do not find conflicting arcs..$^{2}$ In fact, we can read from the representation a model $\mathfrak{M}=\left\langle M, \mathrm{p}^{\mathfrak{M}}\right\rangle$, with $M:=\{\mathrm{u}, \mathrm{v}\}$ and $\mathrm{p}^{\mathfrak{M}}:=\{\mathrm{u}\}$, where one can satisfy $\mathrm{p}(\mathrm{u})$ and $\neg \mathrm{p}(\mathrm{v})$.

Example 2.3. We reduce $\mathrm{p}(\mathrm{v}) \wedge \mathrm{v} \doteq \mathrm{u} \models \mathrm{p}(\mathrm{u})$ to the unsatisfiability of the $\operatorname{set}\{\mathrm{p}(\mathrm{v}) \wedge \mathrm{v} \doteq \mathrm{u}, \neg \mathrm{p}(\mathrm{u})\}$. We have the graphical representations as sets of arcs as follows:

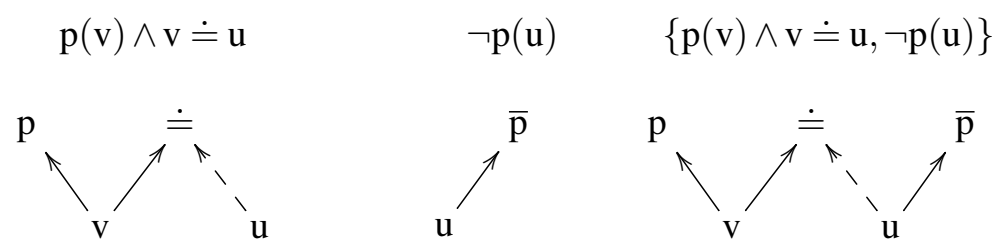

Now, we can simplify the representation of $\{\mathrm{p}(\mathrm{v}) \wedge \mathrm{v} \doteq \mathrm{u}, \neg \mathrm{p}(\mathrm{u})\}$, by renaming $\mathrm{v}$ to $\mathrm{u}$ :

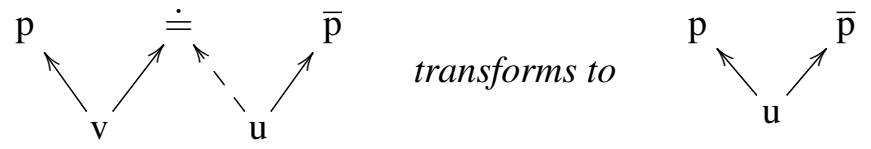

This final representation is not satisfiable (cf. Example 2.1).

Example 2.4. We reduce $\mathrm{r}(\mathrm{u}, \mathrm{v}) \models \exists \mathrm{zr}(\mathrm{u}, \mathrm{z})$ to $\{\mathrm{r}(\mathrm{u}, \mathrm{v}), \neg \exists \mathrm{zr}(\mathrm{u}, \mathrm{z})\} \models \perp$. As before, we can represent formula $\mathrm{r}(\mathrm{u}, \mathrm{v})$ by the single-arc draft:

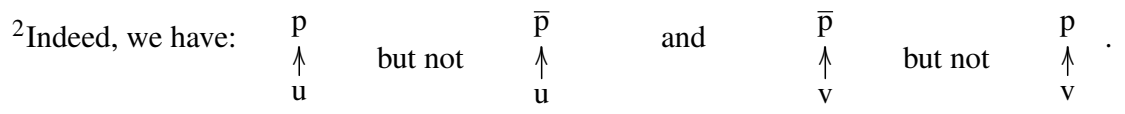




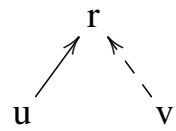

Also, we can represent $\neg \exists \mathrm{zr}(\mathrm{u}, \mathrm{z})$ by the following 1-ary arc:

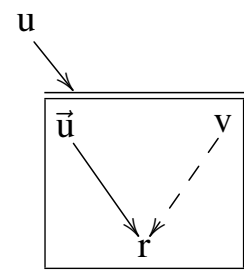

Thus, we can represent $\{\mathrm{r}(\mathrm{u}, \mathrm{v}), \neg \exists \mathrm{zr}(\mathrm{u}, \mathrm{z})\}$ by the draft:

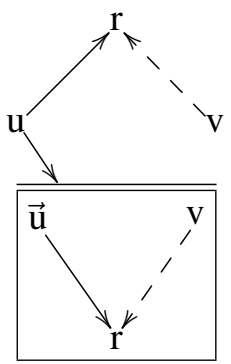

Now, with $\overrightarrow{\mathrm{u}} \mapsto \mathrm{u}, \mathrm{v} \mapsto \mathrm{v}$, we have a copy of the slice under complement within the draft, namely:

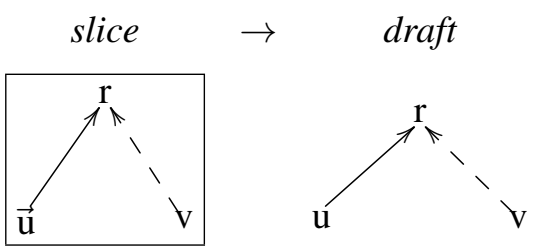

So, the representation of $\{\mathrm{r}(\mathrm{u}, \mathrm{v}), \neg \exists \mathrm{zr}(\mathrm{u}, \mathrm{z})\}$ is not satisfiable.

Example 2.5. We reduce $\exists \mathrm{x} \exists \mathrm{y}[\mathrm{r}(\mathrm{u}, \mathrm{x}) \wedge \mathrm{s}(\mathrm{x}, \mathrm{y})] \models \exists \mathrm{zr}(\mathrm{u}, \mathrm{z})$ to $\{\exists \mathrm{x} \exists \mathrm{y}[\mathrm{r}(\mathrm{u}, \mathrm{x}) \wedge \mathrm{s}(\mathrm{x}, \mathrm{y})], \neg \exists \mathrm{zr}(\mathrm{u}, \mathrm{z})\} \models \perp$. Proceeding as before, we can be represent $\{\exists \mathrm{z} \exists \mathrm{y}[\mathrm{r}(\mathrm{x}, \mathrm{z}) \wedge \mathrm{s}(\mathrm{z}, \mathrm{y})], \neg \exists \mathrm{zr}(\mathrm{u}, \mathrm{z})\}$ as:

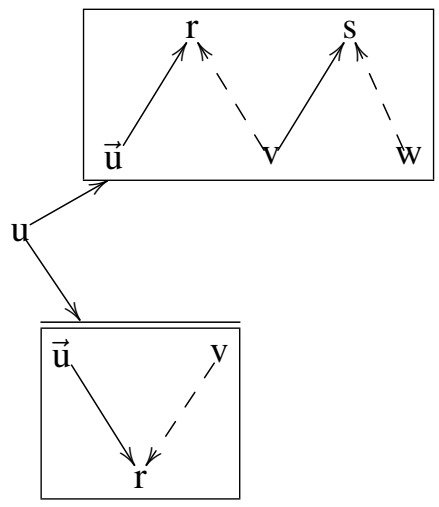

We can transform this representation into the following one, which is, much as before, unsatisfiable. 


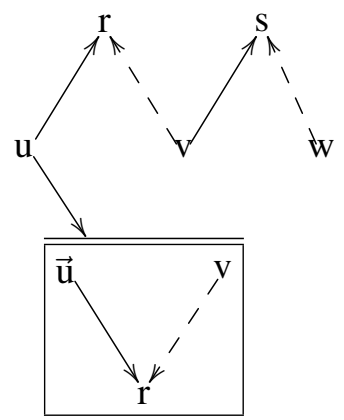

\section{Graph Language}

We now introduce our concepts: expressions, slices and graphs will give relations, whereas arcs, sketches and drafts will correspond to constraints. We will examine syntax and semantics (in 3.1 ) and then some concepts and constructions (in 3.2).

We first introduce some notations. Given a function $f: A \rightarrow B$, we use $f(a)$ or $a^{f}$ for its value at an element $a \in A$; which we extend to lists and sets. For a list $a=\left\langle a_{1}, \ldots, a_{k}\right\rangle \in A^{k}$, we use $f(a)$ or $a^{f}$ for the list of values $\left\langle a_{1}{ }^{f}, \ldots, a_{k}{ }^{f}\right\rangle \in B^{k}$; for a set $\mathrm{N}$, we use $f(\mathrm{~N})$ or $\mathrm{N}^{f}$ for the set of values $\left\{a^{f}: a \in \mathrm{N}\right\}$. Given a list $a=\left\langle a_{1}, \ldots, a_{k}\right\rangle \in A^{k}$, we employ $\underline{a}$ for its set of components. The null list is $\lambda:=\langle\rangle$. We sometimes write a list $\left\langle a_{1}, \ldots, a_{k}\right\rangle$ simply as $a_{1} \ldots a_{k}$.

We will use names (or parameters) for marking free places and variables for marking bound places, as usual in Proof Theory [12]. To quantify a formula $\varphi$ we replace a name $\mathrm{u}$ by a new variable (not appearing in $\varphi$ ) obtaining $\exists \mathrm{x} \varphi[\mathrm{u} / \mathrm{x}]$ and $\forall \mathrm{x} \varphi[\mathrm{u} / \mathrm{x}]$. Also, given lists $\mathrm{u}$, of $n$ distinct names, and $\mathrm{x}$, of $n$ distinct variables not occurring in $\varphi$, we have the formulas $\exists^{n} \mathrm{x} \varphi[\mathrm{u} / \mathrm{x}]$ and $\forall^{n} \mathrm{x} \varphi[\mathrm{u} / \mathrm{x}]$.

We will consider first-order predicate languages (without function symbols, except the constant $\perp$ ), each one characterized by pairwise disjoint sets as follows:

$(\mathrm{Nm})$ an infinite linearly ordered set of names $\mathrm{Nm}$;

( $\mathrm{Vr}$ ) a denumerably infinite set of variables $\mathrm{Vr}$;

(Pr) (possibly empty, but pairwise disjoint) sets $\operatorname{Pr}_{n}$ of $n$-ary predicate symbols, for $n \in \mathbb{N}$.

Given $m \in \mathbb{N}_{+}$, we use $\mathrm{u}_{m}$ for the mth name. Given $n \in \mathbb{N}$, we use $\mathrm{u}^{n}:=\left\langle\mathrm{u}_{1}, \ldots \mathrm{u}_{n}\right\rangle$ for the list of the first $n$ names (with $\mathrm{u}^{0}=\lambda$ ). Also, given a set $\mathrm{v} \subseteq \mathrm{Nm}$ of names, we use $\overrightarrow{\mathrm{v}}$ for the list of the names in $\mathrm{v}$ in the ordering of $\mathrm{Nm}$. For a formula $\varphi$, we use $\mathrm{NF}[\varphi]$ for the set of names occurring in $\varphi$.

\subsection{Syntax and semantics}

We now introduce the syntax and semantics of our concepts. We first examine the syntax of our concepts.

The objects of our graph language are defined by mutual recursion as follows.

(E) An $n$-ary expression is an $n$-ary predicate symbol, a formula with $n$ names, an $n$-ary slice or graph (see below), or $\overline{\mathrm{E}}$, where $\mathrm{E}$ is an $n$-ary expression. For instance, $\perp$ is a 0 -ary expression, $\doteq$ and $\bar{\doteq}$ are 2-ary expressions, whereas $\mathrm{p}(\mathrm{u})$ and $\overline{\mathrm{p}}$ (for $\mathrm{p} \in \operatorname{Pr}_{1}$ ) are 1-ary expressions.

(a) An $m$-ary $\operatorname{arc}$ a over set $\mathrm{N} \subseteq \mathrm{Nm}$ of names is a pair $\mathrm{E} / \mathrm{v}$ (also noted $\frac{\mathrm{E}}{\mathrm{v}}$ ), where $\mathrm{E}$ is an $m$-ary expression and $\mathrm{v} \in \mathrm{N}^{m}$. Examples are $\perp / \lambda, \doteq / \mathrm{uv}, \overline{\mathrm{p}} / \mathrm{u}, \mathrm{q}(\mathrm{u}) / \mathrm{v}$ (for $\mathrm{p}, \mathrm{q} \in \operatorname{Pr}_{1}$ ) and $\mathrm{s} / \mathrm{u}$ w (for $\mathrm{s} \in \operatorname{Pr}_{2}$ ).

( $\Sigma$ ) A sketch $\Sigma=\langle\mathrm{N}, \mathrm{A}\rangle$ consists of sets $\mathrm{N} \subseteq \mathrm{Nm}$ of names and $\mathrm{A}$ of $\operatorname{arcs}$ over $\mathrm{N}$. 
(D) A draft $\mathrm{D}=\langle\mathrm{N}, \mathrm{A}\rangle$ is a sketch with finite sets $\mathrm{N}$ of names and $\mathrm{A}$ of arcs. An example of draft is $\mathrm{D}^{\prime}=\left\langle\left\{\mathrm{u}, \mathrm{u}^{\prime}, \mathrm{v}, \mathrm{w}, \mathrm{w}^{\prime}\right\},\left\{\overline{\mathrm{p}} / \mathrm{u}, \mathrm{q}(\mathrm{u}) / \mathrm{v}, \doteq / \mathrm{ww}^{\prime}, \mathrm{s} / \mathrm{u} w\right\}\right\rangle$.

(S) An $n$-ary slice $\mathrm{S}=\langle\underline{\mathrm{S}}: \hat{\mathrm{s}}\rangle$ consists of its underlying draft $\underline{\mathrm{S}}:=\langle\mathrm{N}, \mathrm{A}\rangle$ and a distinguished list $\hat{\mathrm{s}}$, with $\hat{\mathrm{s}} \in \mathrm{N}^{n}$. For instance, $\mathrm{S}=\left\langle\left\{\mathrm{u}, \mathrm{u}^{\prime}, \mathrm{v}, \mathrm{w}, \mathrm{w}^{\prime}\right\},\left\{\overline{\mathrm{p}} / \mathrm{u}, \mathrm{q}(\mathrm{u}) / \mathrm{v}, \doteq / \mathrm{w} \mathrm{w}^{\prime}, \mathrm{s} / \mathrm{u} w\right\}: \mathrm{uvv}\right\rangle$ is a 3-ary slice with underlying draft $\underline{\mathrm{S}}=\mathrm{D}^{\prime}$ (as above) and distinguished list $\hat{\mathrm{s}}=\langle\mathrm{u}, \mathrm{v}, \mathrm{v}\rangle$.

(G) An $n$-ary graph is a finite set of $n$-ary slices.

In particular, the empty graph \{\} has no slice. Example 4.5 (in 4.2) will show a 2-slice graph.

Note that expressions, arcs, slices and graphs are finite objects, whereas sketches are not necessarily so. Sketches will be useful for representing models and constructing co-limits. Also, some concepts and results do not depend on finiteness (see 3.2), which will be important in Section 4. We wish to represent these finite objects graphically by drawings (cf. the examples in Section 2). For this purpose, we employ two sorts of nodes: name nodes (labeled by names) and expression nodes (labeled by expressions). Some representations aiming at precision and readability are as follows.

We represent an $m$-ary arc $\mathrm{E} / \mathrm{v}$, with $\mathrm{v}=\left\langle\mathrm{v}_{1}, \ldots, \mathrm{v}_{m}\right\rangle$, by $m$ arrows connecting each node labeled by $\mathrm{v}_{i}$ to the node labeled by E. For instance, we can draw a 3 -ary $\operatorname{arct} \mathrm{t} /\langle\mathrm{u}, \mathrm{v}, \mathrm{w}\rangle$ as

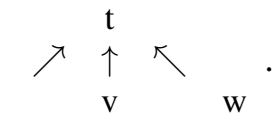
To clarify (as in $\frac{\mathrm{t}}{\mathrm{uvu}}$ ), we may use distinct kinds of lines or label them by numbers 3 A more compact version uses is $\mathrm{v}_{1} \stackrel{\mathrm{r}}{\rightarrow} \mathrm{v}_{2}$ for the 2-arc $\mathrm{r} / \mathrm{v}_{1} \mathrm{v}_{2}$, representing 1-ary, 3-ary and 4-ary arcs, respectively, as:

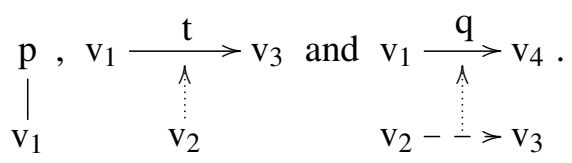

We can indicate the components of a distinguished list by marking their nodes, say with numbers, e. g. $\langle u, v, u\rangle$ by $u^{1,3} v^{2}$. Also, it may be convenient (for easier visualization) to enclose a slice $S$ within a full box, $S$, and a graph $G$ within a dashed box, $\mathrm{G}$. For instance, Example 2.5 (in Section 2 shows a 0-ary slice $S=\langle\{\mathrm{u}, \mathrm{v}, \mathrm{w}\}, \mathrm{A}: \lambda\rangle$, with $\mathrm{A}=\{\mathrm{r} / \mathrm{uv}, \mathrm{s} / \mathrm{vw}, \overline{\mathrm{T}} / \mathrm{u}\}$, where $\mathrm{T}$ is the 1-ary slice $\langle\{\mathrm{u}, \mathrm{v}\},\{\mathrm{r} / \mathrm{uv}\}: \mathrm{u}\rangle$.

Given a list $\mathrm{w}$ of names, the arcless $\mathrm{w}$ slice is the slice $T_{\mathrm{w}}:=\langle\underline{\mathrm{w}}, \emptyset: \mathrm{w}\rangle$. The arcless $m$-ary slice is the slice $\top_{m}:=\top_{\mathrm{u}^{m}}\left(\mathrm{u}^{m}\right.$ is the list of the first $m$ names) and the m-node arcless draft is $\top_{m}=\left\langle\underline{\mathbf{u}^{m}}, \emptyset\right\rangle$. The arc of formula $\varphi$, with set $\mathrm{v}$ of names, is $\mathrm{a}[\varphi]:=\varphi / \overrightarrow{\mathrm{v}}$. (The arc of a sentence $\tau$ is 0 -ary: $\mathrm{a}[\tau]=\tau / \lambda$, which we represent as the expression node $\tau$.) The sketch of the set of $\operatorname{arcs} A$ is the sketch $S k[A]:=\langle N, A\rangle$, where $N$ consists of the names occurring in the $\operatorname{arcs}$ of $A: N:=\bigcup\{\underline{w} \subseteq N m: E / w \in A\}$. For instance, $\mathrm{Sk}[\{\mathrm{s} / \mathrm{uv}, \mathrm{p}(\mathrm{v}) / \mathrm{w}\}]=\langle\{\mathrm{u}, \mathrm{v}, \mathrm{w}\},\{\mathrm{s} / \mathrm{uv}, \mathrm{p}(\mathrm{v}) / \mathrm{w}\}\rangle$.

We may wish to add an arc $\mathrm{a}=\mathrm{E} / \mathrm{v}$ to a sketch, a slice or a graph. For a sketch $\Sigma=\langle\mathrm{N}, \mathrm{A}\rangle$, we set $\Sigma+\mathrm{a}:=\langle\mathrm{N} \cup \underline{\mathrm{v}}, \mathrm{A} \cup\{\mathrm{a}\}\rangle$; for a slice $\mathrm{S}=\langle\underline{\mathrm{S}}: \hat{\mathrm{s}}\rangle$, we set $\mathrm{S}+\mathrm{a}:=\langle\underline{\mathrm{S}}+\mathrm{a}: \hat{\mathrm{s}}\rangle$; for a graph $\mathrm{G}$, we set $\mathrm{G}+\mathrm{a}:=\{\mathrm{S}+\mathrm{a}: \mathrm{S} \in \mathrm{G}\}$. The difference slice of a finite set of arcs $\mathrm{A}$ with respect to an $\operatorname{arc} \mathrm{a}=\mathrm{E} / \mathrm{v}$ is the 0 -ary slice $\mathrm{DS}[\mathrm{A} \angle \mathrm{a}]:=\langle\mathrm{Sk}[\mathrm{A}]+\overline{\mathrm{E}} / \mathrm{v}: \lambda\rangle$. For instance, Example 2.3 (in Section 2 represents the set $\{\mathrm{p}(\mathrm{v}) \wedge \mathrm{v} \doteq \mathrm{u}, \neg \mathrm{p}(\mathrm{u})\}$ by the difference slice $\operatorname{DS}[\{\mathrm{p} / \mathrm{v}, \doteq / \mathrm{vu}\} \angle \mathrm{p} / \mathrm{u}]$. We will give some intuition for using 0 -ary slices in 3.2 .

We now examine the semantics of our concepts and related ideas.

A model $\mathfrak{M}$ has as its universe a set $M \neq \emptyset$ and realizes each $n$-ary predicate symbol $\mathrm{p} \in \operatorname{Pr}_{n}$ as an $n$-ary relation $\mathrm{p}^{\mathfrak{M}} \subseteq M^{n}$ (with $\stackrel{\mathfrak{M}}{ }^{\mathfrak{M}}:=\left\{\langle a, a\rangle \in M^{2}: a \in M\right\}$ ). An $M$-assignment for set $\mathrm{N} \subseteq \mathrm{Nm}$ of names is a function $\mathrm{g}: \mathrm{N} \rightarrow M$. A formula $\varphi$ with set $\mathrm{v}$ of $n$ names defines the $n$-ary relation $\varphi^{\mathfrak{M}} \subseteq M^{n}$ consisting

\footnotetext{
${ }^{3}$ We often employ full, dashed, dotted and wavy lines, respectively, for the 1st, 2nd, 3rd and 4th arguments of expressions.
} 
of the values of its ordered names for the assignments satisfying $\varphi: \varphi^{\mathfrak{M}}:=\left\{\vec{v}^{\mathrm{h}} \in M^{n}: \mathfrak{M} \models \varphi[[\mathrm{h}]\}\right.$. For instance, for 2-ary predicate symbol $\mathrm{r}, \mathrm{r}\left(\mathrm{u}_{1}, \mathrm{u}_{2}\right)^{\mathfrak{M}}=\mathrm{r}^{\mathfrak{M}}, \mathrm{r}\left(\mathrm{u}_{2}, \mathrm{u}_{1}\right)^{\mathfrak{M}}=\left\{\langle b, a\rangle \in M^{2}:\langle a, b\rangle \in \mathrm{r}^{\mathfrak{M}}\right\}$ and $\mathrm{r}\left(\mathrm{u}_{1}, \mathrm{u}_{1}\right)^{\mathfrak{M}}=\left\{\langle a\rangle \in M^{1}:\langle a, a\rangle \in \mathrm{r}^{\mathfrak{M}}\right\}$. Also, $\perp^{\mathfrak{M}}:=\emptyset$.

We now introduce the meanings of the concepts, again by mutual recursion.

(E) We define the relation of an expression as follows. For a predicate symbol $\mathrm{p}$ we have its relation: $[\mathrm{p}]_{\mathfrak{M}}:=\mathrm{p}^{\mathfrak{M}}$; for formula $\varphi$ we have its defined relation: $[\varphi]_{\mathfrak{M}}:=\varphi^{\mathfrak{M}}$; for a slice $S$ or graph $\mathrm{G}$, we use the extensions: $[\mathrm{S}]_{\mathfrak{M}}:=\left[[\mathrm{S}]_{\mathfrak{M}}\right.$ and $[\mathrm{G}]_{\mathfrak{M}}:=\left[[\mathrm{G}]_{\mathfrak{M}}\right.$ (see below); for $\overline{\mathrm{E}}$, where $\mathrm{E}$ is an $n$-ary expression, we use the complement: $[\overline{\mathrm{E}}]_{\mathfrak{M}}:=M^{n} \backslash[\mathrm{E}]_{\mathfrak{M}}$.

(a) An M-assignment $\mathrm{g}: \mathrm{N} \rightarrow M$ satisfies an $m$-ary $\operatorname{arc} \mathrm{E} / \mathrm{v}$ over $\mathrm{N}$ in $\mathfrak{M}$ (noted $\mathrm{g} \vdash_{\mathfrak{M}} \mathrm{E} / \mathrm{v}$ ) iff $\mathrm{v} \in \mathrm{N}^{m}$ and $\mathrm{v}^{\mathrm{g}} \in[\mathrm{E}]_{\mathfrak{M}}$. For instance, $\mathrm{g} \Vdash_{\mathfrak{M}} \doteq / \mathrm{u}$ iff $\mathrm{u}^{\mathrm{g}}=\mathrm{v}^{\mathrm{g}}$ and $\mathrm{g} \vdash_{\mathfrak{M}} \mathrm{p} / \mathrm{w}$ iff $\mathrm{w}^{\mathrm{g}} \in[\mathrm{p}]_{\mathfrak{M}}=\mathrm{p}^{\mathfrak{M}}$.

( $\Sigma$ ) An assignment g satisfies a sketch $\Sigma=\langle\mathrm{N}, \mathrm{A}\rangle$ in $\mathfrak{M}$ (noted $\mathrm{g}: \Sigma \rightarrow \mathfrak{M}$ ) iff g satisfies every arc a $\in \mathrm{A}$.

(S) The extension of a slice is the relation consisting of values of its distinguished list for the assignments satisfying its underlying draft; for an $n$-ary slice $\mathrm{S}=\langle\underline{\mathrm{S}}: \hat{\mathrm{s}}\rangle,[[\mathrm{S}]]_{\mathfrak{M}}:=\left\{\hat{\mathrm{s}}^{\mathrm{g}} \in M^{n}: \mathrm{g}: \underline{\mathrm{S}} \rightarrow \mathfrak{M}\right\}$.

(G) The extension of a graph is the union of those of its slices: $\left[[G]_{\mathfrak{M}}:=\bigcup_{S \in G}\left[[S]_{\mathfrak{M}}\right.\right.$.

Clearly, $\mathrm{g} \Vdash_{\mathfrak{M}} \overline{\mathrm{E}} / \mathrm{v}$ iff $\mathrm{g} \forall_{\mathfrak{M}} \mathrm{E} / \mathrm{v}$. Also, the arcless $m$-ary slice $\top_{m}$ has extension $\left[\left[\top_{m}\right]_{\mathfrak{M}}=M^{m}\right.$.

An expression $\mathrm{E}$ is null iff $[\mathrm{E}]_{\mathfrak{M}}=\emptyset$ in every model $\mathfrak{M}$. For instance, the empty graph \{\} is null.

Given a sketch $\Sigma=\langle\mathrm{N}, \mathrm{A}\rangle$ and an arc a $=\mathrm{E} / \mathrm{v}$, we say that a is a consequence of $\Sigma$ (noted $\Sigma \mid=\mathrm{a}$ )

iff, for every model $\mathfrak{M}$ and $M$-assignment $\mathrm{g}: \mathrm{N} \cup \underline{\mathrm{v}} \rightarrow M$, g satisfies a whenever $\mathrm{g}$ satisfies $\Sigma$. Call expressions $\mathrm{E}$ and $\mathrm{F}$ equivalent (noted $\mathrm{E} \equiv \mathrm{F}$ ) iff, for every model $\mathfrak{M},[\mathrm{E}]_{\mathfrak{M}}=[\mathrm{F}]_{\mathfrak{M}}$. A slice $\mathrm{S}$ and the singleton graph $\{\mathrm{S}\}$ are equivalent (so they may be identified).

We can reduce consequence to the difference slice: an arc a is a consequence of a draft D iff the difference slice DS $[A \angle a]$ is null. So, we can also reduce logical consequence to a difference slice ${ }^{4}$

Proposition 3.1. Given a finite set $\Psi$ of formulas and a formula $\theta: \Psi \models \theta$ iff the difference slice $\mathrm{DS}[\{\mathrm{a}[\psi]: \psi \in \Psi\} \angle \mathrm{a}[\theta]]$ is null.

Proof. By the preceding remark, since $\mathrm{g} \Vdash_{\mathfrak{M}} \mathrm{a}[\varphi]$ iff $\mathfrak{M}=\varphi[[\mathrm{g}]$.

Section 4 will present a calculus for establishing that an expression is null.

\subsection{Concepts and constructions}

We now examine some concepts and constructions.

We first introduce morphisms for comparing sketches.

Consider sketches $\Sigma^{\prime}=\left\langle\mathrm{N}^{\prime}, \mathrm{A}^{\prime}\right\rangle$ and $\Sigma^{\prime \prime}=\left\langle\mathrm{N}^{\prime \prime}, \mathrm{A}^{\prime \prime}\right\rangle$. A function $\eta: \mathrm{N}^{\prime \prime} \rightarrow \mathrm{N}^{\prime}$ is a morphism from $\Sigma^{\prime \prime}$ to $\Sigma^{\prime}$ (noted $\eta: \Sigma^{\prime \prime} \rightarrow \Sigma^{\prime}$ ) iff it preserves arcs: for every arc $E / v \in A^{\prime \prime}$, we have $E / v^{\eta} \in A^{\prime}$. We use $\operatorname{Mor}\left[\Sigma^{\prime \prime}, \Sigma^{\prime}\right]$ for the set of morphisms from $\Sigma^{\prime \prime}$ to $\Sigma^{\prime}$.

Example 3.1. Given $\mathrm{p} \in \operatorname{Pr}_{1}$ and $\mathrm{q}, \mathrm{r}, \mathrm{s}, \mathrm{t}, \mathrm{a}, \mathrm{b} \in \operatorname{Pr}_{2}$, consider the drafts $\mathrm{D}^{\prime}=\left\langle\mathrm{N}^{\prime}, \mathrm{A}^{\prime}\right\rangle$ and $\mathrm{D}^{\prime \prime}=\left\langle\mathrm{N}^{\prime \prime}, \mathrm{A}^{\prime \prime}\right\rangle$, with sets of nodes $\mathrm{N}^{\prime}=\left\{\mathrm{u}, \mathrm{v}, \mathrm{v}^{\prime}, \mathrm{w}, \mathrm{w}^{\prime}\right\}$ and $\mathrm{N}^{\prime \prime}=\left\{\mathrm{u}_{1}, \mathrm{u}_{2}, \mathrm{u}_{3}, \mathrm{v}, \mathrm{v}_{1}, \mathrm{v}_{2}, \mathrm{w}, \mathrm{w}_{1}, \mathrm{w}_{2}, \mathrm{w}^{\prime}\right\}$, and sets of arcs

$$
\mathrm{A}^{\prime}=\left\{\mathrm{q} / \mathrm{vw}, \mathrm{p} / \mathrm{w}^{\prime}, \mathrm{r} / \mathrm{vw}^{\prime}, \mathrm{s} / \mathrm{vu}, \mathrm{t} / \mathrm{uw}, \mathrm{a} / \mathrm{uv}^{\prime}, \mathrm{b} / \mathrm{v}^{\prime} \mathrm{w}\right\} \text { and }
$$

$A^{\prime \prime}=\left\{\mathrm{q} / \mathrm{v}_{1} \mathrm{w}_{1}, \mathrm{q} / \mathrm{v}_{2} \mathrm{w}_{2}, \mathrm{p} / \mathrm{w}^{\prime}, \mathrm{r} / \mathrm{vw}^{\prime}, \mathrm{r} / \mathrm{v}_{1} \mathrm{w}^{\prime}, \mathrm{r} / \mathrm{v}_{2} \mathrm{w}^{\prime}, \mathrm{s} / \mathrm{v}_{2} \mathrm{u}_{3}, \mathrm{t} / \mathrm{u}_{2} \mathrm{w}_{1}, \mathrm{a} / \mathrm{u}_{1} \mathrm{v}^{\prime}, \mathrm{a} / \mathrm{u}_{3} \mathrm{v}^{\prime}, \mathrm{b} / \mathrm{v}^{\prime} \mathrm{w}, \mathrm{b} / \mathrm{v}^{\prime} \mathrm{w}_{1}, \mathrm{~b} / \mathrm{v}^{\prime} \mathrm{w}_{2}\right\}$.

\footnotetext{
${ }^{4}$ Recall that $\Psi=\theta$ iff, for every model $\mathfrak{M}$ and assignment $\mathrm{h}$, h satisfies $\theta$ whenever h satisfies every $\psi \in \Psi$.
} 
These drafts $\mathrm{D}^{\prime}$ and $\mathrm{D}^{\prime \prime}$ can be represented as in Figure 1 The mapping $\mathrm{v}^{\prime} \mapsto \mathrm{v}^{\prime} ; \mathrm{w}^{\prime} \mapsto \mathrm{w}^{\prime} ; \mathrm{v}, \mathrm{v}_{1}, \mathrm{v}_{2} \mapsto \mathrm{v}$; $\mathrm{w}, \mathrm{w}_{1}, \mathrm{w}_{2} \mapsto \mathrm{w}$ and $\mathrm{u}_{1}, \mathrm{u}_{2}, \mathrm{u}_{3} \mapsto \mathrm{u}$ preserves arcs ${ }^{5}$ So, we have a morphism $\eta: \mathrm{D}^{\prime \prime} \rightarrow \mathrm{D}^{\prime}$. We also have formulas $\delta\left(\mathrm{D}^{\prime}\right)$ and $\delta\left(\mathrm{D}^{\prime \prime}\right)$ such that $\mathrm{g}: \mathrm{D}^{\prime} \rightarrow \mathfrak{M}$ iff $\left.\mathfrak{M}=\delta\left(\mathrm{D}^{\prime}\right)[\mathrm{g}]\right]$ and $\mathrm{g}: \mathrm{D}^{\prime \prime} \rightarrow \mathfrak{M}$ iff $\left.\mathfrak{M}=\delta\left(\mathrm{D}^{\prime \prime}\right)[\mathrm{g}]\right]^{6}$
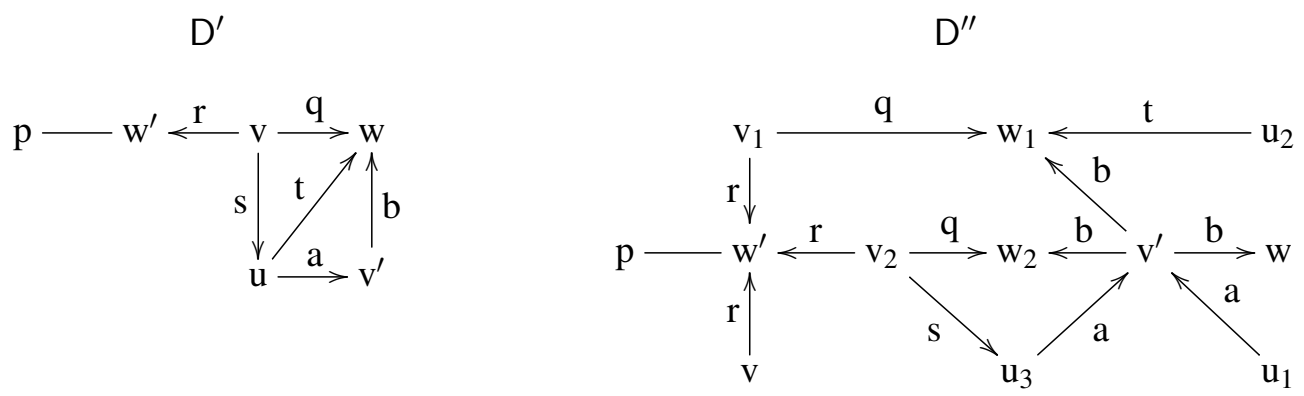

Figure 1: Drafts D' and D" (Example 3.1)

A morphism transfers satisfying assignments by composition.

Lemma 3.1. Given a morphism $\eta: \Sigma^{\prime \prime} \rightarrow \Sigma^{\prime}$, for every assignment $\mathrm{g}: \mathrm{N}_{\Sigma^{\prime}} \rightarrow M$ satisfying $\Sigma^{\prime}$, the composite $\mathrm{g} \cdot \eta: \mathrm{N}_{\Sigma^{\prime \prime}} \rightarrow M$ is an assignment satisfying $\Sigma^{\prime \prime}$.

Proof. For every arc $\mathrm{E} / \mathrm{v} \in \mathrm{A}_{\Sigma^{\prime \prime}}$, we have $\mathrm{E} / \mathrm{v}^{\eta} \in \mathrm{A}_{\Sigma^{\prime}}$, thus $\mathrm{v}^{\mathrm{g} \cdot \eta} \in[\mathrm{E}]_{\mathfrak{M}}$, whence $\mathrm{g} \cdot \eta \vdash_{\mathfrak{M}} \mathrm{E} / \mathrm{v}$.

We now use morphisms to introduce zero sketches, slices and graphs.

A sketch $\Sigma=\langle N, A\rangle$ is zero iff there exist a slice $T=\langle\underline{T}: \hat{t}\rangle$ and a morphism $\eta: \underline{T} \rightarrow \Sigma$ such that $\bar{T} / \hat{t}^{\eta}$ is an arc in $A$. A slice $S$ is zero iff its underlying draft $\underline{S}$ is a zero sketch. A graph is zero iff all its slices are zero slices. The sets of zero drafts, zero slices and zero graphs are all decidable, since, for drafts $D^{\prime}$ and $D^{\prime \prime}$, the set $\operatorname{Mor}\left[D^{\prime \prime}, D^{\prime}\right]$ is finite.

Example 3.2. Consider the following draft $\mathrm{D}$ and 2-ary slice $\mathrm{T}$ :
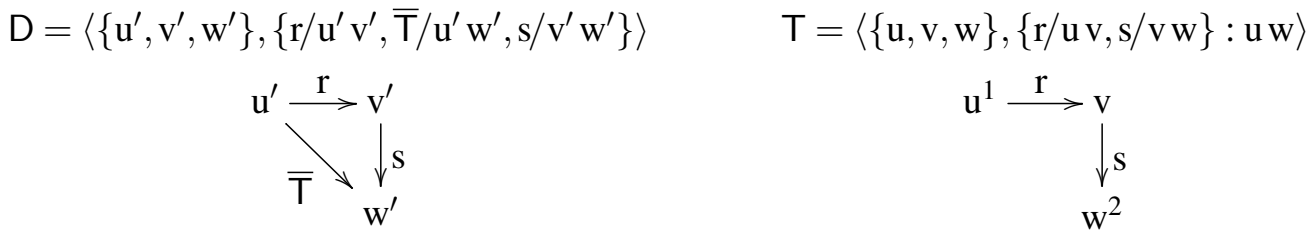

The mapping $\mathrm{u} \mapsto \mathrm{u}^{\prime}, \mathrm{v} \mapsto \mathrm{v}^{\prime}, \mathrm{w} \mapsto \mathrm{w}^{\prime}$ gives a morphism $\eta: \underline{\mathrm{T}} \rightarrow \mathrm{D}$, with $\hat{\mathrm{t}}^{\eta}=\left\langle\mathrm{u}^{\eta}, \mathrm{w}^{\eta}\right\rangle=\left\langle\mathrm{u}^{\prime}, \mathrm{w}^{\prime}\right\rangle$. Thus, draft $\mathrm{D}$ is zero. So, slices $\langle\mathrm{D}: \lambda\rangle,\left\langle\mathrm{D}: \mathrm{u}^{\prime}\right\rangle,\left\langle\mathrm{D}: \mathrm{v}^{\prime} \mathrm{w}^{\prime}\right\rangle$ and $\left\langle\mathrm{D}: \mathrm{u}^{\prime}\right\rangle,\left\langle\mathrm{D}: \mathrm{u}^{\prime} \mathrm{v}^{\prime} \mathrm{w}^{\prime}\right\rangle$ are zero slices. $\left.{ }^{7}\right]$

Lemma 3.2. No assignment can satisfy a zero sketch.

Proof. By Lemma 3.1, $\mathrm{g}: \Sigma \rightarrow \mathfrak{M}$ yields $\mathrm{g} \cdot \eta: \underline{\mathrm{T}} \rightarrow \mathfrak{M}$, thus $\mathrm{g} \Vdash_{\mathfrak{M}} \mathrm{T} / \hat{\mathrm{t}}^{\eta}$ whence $\mathrm{g} \| \nvdash_{\mathfrak{M}} \overline{\mathrm{T}} / \hat{\mathrm{t}}^{\eta}$.

Corollary 3.1. Zero slices and zero graphs are null.

Proof. By Lemma 3.2 ; if $[[\mathrm{S}]]_{\mathfrak{M}} \neq \emptyset$, then some assignment satisfies $\underline{\mathrm{S}}$.

\footnotetext{
${ }^{5}$ For instance, for $\operatorname{arc} \mathrm{p} / \mathrm{w}$ of $\mathrm{D}^{\prime \prime}$, we have $\operatorname{arc} \mathrm{p} / \mathrm{w}^{\prime}$ of $\mathrm{D}^{\prime}$; for $\operatorname{arcs} \mathrm{q} / \mathrm{v}_{1} \mathrm{w}_{1}$ and $\mathrm{q} / \mathrm{v}_{2} \mathrm{w}_{2}$ of $\mathrm{D}^{\prime \prime}$, we have $\operatorname{arc} \mathrm{q} / \mathrm{vw}$ of $\mathrm{D}^{\prime}$.

${ }^{6}$ Take $\delta\left(\mathrm{D}^{\prime}\right)$ as $\mathrm{q}(\mathrm{v}, \mathrm{w}) \wedge \mathrm{p}\left(\mathrm{w}^{\prime}\right) \wedge \mathrm{r}\left(\mathrm{v}, \mathrm{w}^{\prime}\right) \wedge \mathrm{s}(\mathrm{v}, \mathrm{u}) \wedge \mathrm{t}(\mathrm{u}, \mathrm{w}) \wedge \mathrm{a}\left(\mathrm{u}, \mathrm{v}^{\prime}\right) \wedge \mathrm{b}\left(\mathrm{v}^{\prime}, \mathrm{w}\right)$ and $\delta\left(\mathrm{D}^{\prime \prime}\right)$ as the conjunction of $\mathrm{q}\left(\mathrm{v}_{1}, \mathrm{w}_{1}\right)$, $\mathrm{q}\left(\mathrm{v}_{2}, \mathrm{w}_{2}\right), \mathrm{p}\left(\mathrm{w}^{\prime}\right), \mathrm{r}\left(\mathrm{v}, \mathrm{w}^{\prime}\right), \mathrm{r}\left(\mathrm{v}_{1}, \mathrm{w}^{\prime}\right), \mathrm{r}\left(\mathrm{v}_{2}, \mathrm{w}^{\prime}\right), \mathrm{s}\left(\mathrm{v}_{2}, \mathrm{u}_{3}\right), \mathrm{t}\left(\mathrm{u}_{2}, \mathrm{w}_{1}\right), \mathrm{a}\left(\mathrm{u}_{1}, \mathrm{v}^{\prime}\right), \mathrm{a}\left(\mathrm{u}_{3}, \mathrm{v}^{\prime}\right), \mathrm{b}\left(\mathrm{v}^{\prime}, \mathrm{w}\right), \mathrm{b}\left(\mathrm{v}^{\prime}, \mathrm{w}_{1}\right)$ and $\mathrm{b}\left(\mathrm{v}^{\prime}, \mathrm{w}_{2}\right)$.

${ }^{7}$ The extension of slice $T$ can be described by the formula $\exists y(r(u, y) \wedge \mathrm{s}(\mathrm{y}, \mathrm{w}))$.
} 
We can now clarify the intuition behind using 0 -ary difference slices (cf. 3.1). We know that a formula is satisfiable iff its existential closure is so. The latter will convert to a 0 -ary (basic) graph, by Proposition 4.1 (in 4.1). Now, whether a slice is zero does not hinge on its distinguished list.

We now examine some categorical constructions: co-limits and pushouts [8].

The category of sketches and morphisms has co-limits. Given a diagram of sketches $\Sigma_{i}=\left\langle\mathrm{N}_{i}, \mathrm{~A}_{i}\right\rangle$, its co-limit can be obtained as expected: obtain the co-limit $\mathrm{N}$ of the sets of names $\mathrm{N}_{i}$ and then transfer arcs, by the functions $v_{i}: \mathrm{N}_{i} \rightarrow \mathrm{N}$, i. e. $\mathrm{A}:=\bigcup_{i \in I} \mathrm{~A}_{i}{ }^{v_{i}}$. In particular, the pushout of drafts gives a draft.

We wish to glue a slice $T$ onto a draft or a slice via a designated list of names. This involves adding the arcs of $T$ with its distinguished list identified to the designated list of names.

Gluing can be introduced as an amalgamated sum (of drafts). Consider an $m$-ary slice $T=\langle\underline{T}: \hat{t}\rangle$. Given a draft $\mathrm{D}=\langle\mathrm{N}, \mathrm{A}\rangle$ and a list $\mathrm{w} \in \mathrm{N}^{m}$ of $m$ names, the glued draft $\mathrm{D}^{\mathrm{w}} \mathrm{T}$ is the pushout of the drafts $\mathrm{D}+\underline{\mathrm{w}}:=\langle\mathrm{N} \cup \underline{\mathrm{w}}, \mathrm{A}\rangle$ and $\underline{\mathrm{T}}$ over the $m$-ary arcless draft $T_{m}=\left\langle\underline{\mathrm{u}^{m}}, \emptyset\right\rangle$ and the natural morphisms $\mu^{\prime}$ and $\mu^{\prime \prime}\left(\mu^{\prime}: \mathrm{u}_{i} \mapsto \mathrm{w}_{i}\right.$ and $\left.\mu^{\prime \prime}: \mathrm{u}_{i} \mapsto \hat{\mathrm{t}}_{i}\right)$, as shown in Figure 2, Note that $\mathrm{v}^{\prime}(\mathrm{w})=\mathrm{v}^{\prime \prime}(\hat{\mathrm{t}})$.

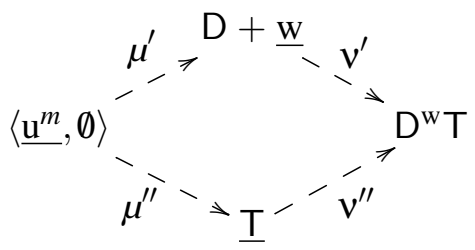

Figure 2: Pushout of drafts

Given an $n$-ary slice $S=\langle\underline{S}: \hat{s}\rangle$, we obtain the glued slice $S^{w} T$ by transferring the distinguished list of $S$ to the glued draft $\underline{S}^{\mathrm{w}} T: S^{\mathrm{w}} T:=\left.\left\langle\underline{S}^{\mathrm{w}} T: v^{\prime}(\hat{\mathrm{s}})\right\rangle\right|^{8}$ We glue a graph by gluing its slices, i. e. $\mathrm{S}^{\mathrm{w}} \mathrm{H}$ is the graph $\left\{S^{w} T: T \in H\right\}$. We glue onto a graph by gluing onto its slices, i. e. $G^{w} H:=\bigcup_{S \in G} S^{w} H$.

Example 3.3. Consider the three slices: 1-ary $\mathrm{S}=\left\langle\left\{\mathrm{u}, \mathrm{u}^{\prime}, \mathrm{v}^{\prime}, \mathrm{v}\right\},\left\{\mathrm{r} / \mathrm{uu}^{\prime}, \mathrm{s} / \mathrm{u}^{\prime} \mathrm{v}^{\prime}, \mathrm{t} / \mathrm{v}^{\prime} \mathrm{v}\right\}: \mathrm{u}\right\rangle$ as well as 2-ary $\mathrm{T}^{\prime}=\langle\{\mathrm{v}, \mathrm{w}\},\{\mathrm{a} / \mathrm{w} \mathrm{v}\}: \mathrm{w} \mathrm{v}\rangle$ and $\mathrm{T}^{\prime \prime}=\langle\{\mathrm{w}\},\{\mathrm{p} / \mathrm{w}, \mathrm{q} / \mathrm{w}\}: \mathrm{w} \mathrm{w}\rangle \cdot{ }^{9}$ They are represented as follows:

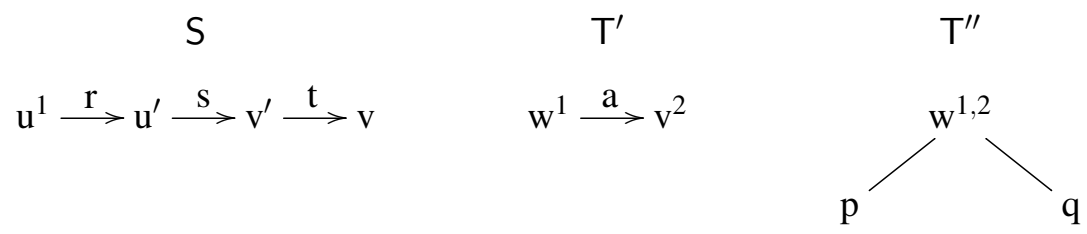

We obtain 1-ary glued slices as follows:

$$
\mathrm{S}^{\left\langle\mathrm{u}^{\prime}, \mathrm{v}^{\prime}\right\rangle} \mathrm{T}^{\prime}=\left\langle\left\{\mathrm{u}, \mathrm{u}^{\prime}, \mathrm{v}^{\prime}, \mathrm{v}\right\},\left\{\begin{array}{c}
\mathrm{r} / \mathrm{uu}, \mathrm{s} / \mathrm{u}^{\prime} \mathrm{v}^{\prime}, \mathrm{t} / \mathrm{v}^{\prime} \mathrm{v}, \\
\mathrm{a} / \mathrm{u}^{\prime} \mathrm{v}^{\prime}
\end{array}\right\}: \mathrm{u}\right\rangle \quad \mathrm{S}^{\left\langle\mathrm{u}^{\prime}, \mathrm{v}^{\prime}\right\rangle} \mathrm{T}^{\prime \prime}=\left\langle\left\{\begin{array}{c}
\mathrm{u}, \mathrm{v}, \\
\mathrm{w}
\end{array}\right\},\left\{\begin{array}{c}
\mathrm{r} / \mathrm{uw}, \mathrm{s} / \mathrm{ww}, \mathrm{t} / \mathrm{wv}, \\
\mathrm{p} / \mathrm{w}, \mathrm{q} / \mathrm{w}
\end{array}\right\}: \mathrm{u}\right\rangle
$$

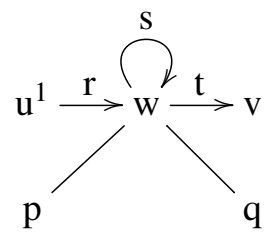

\footnotetext{
${ }^{8} \mathrm{~A}$ glued draft and slice are unique up to isomorphism. They can be made unique by a suitable choice of names. As isomorphic objects have the same behavior, we often consider a sketch or a slice up to isomorphism.

${ }^{9}$ The extension of slice $\mathrm{T}^{\prime \prime}$ can be described by the formula $\mathrm{p}(\mathrm{w}) \wedge \mathrm{q}(\mathrm{w}) \wedge \mathrm{w} \doteq \mathrm{w}^{\prime}$.
} 
Addition of a slice-arc is equivalent to gluing the slice. For instance, with the slices of Example 3.3 $\mathrm{S}+\mathrm{T}^{\prime} / \mathrm{u}^{\prime} \mathrm{v}^{\prime} \equiv \mathrm{S}^{\left\langle\mathrm{u}^{\prime}, \mathrm{v}^{\prime}\right\rangle} \mathrm{T}^{\prime}$ and $\mathrm{S}+\mathrm{T}^{\prime \prime} / \mathrm{u}^{\prime} \mathrm{v}^{\prime} \equiv \mathrm{S}^{\left\langle\mathrm{u}^{\prime}, \mathrm{v}^{\prime}\right\rangle} \mathrm{T}^{\prime \prime}$.

Proposition 3.2. Given a slice $\mathrm{S}$ and $\operatorname{an} \operatorname{arc} \mathrm{T} / \mathrm{w}: \mathrm{S}+\mathrm{T} / \mathrm{w} \equiv \mathrm{S}^{\mathrm{w}} \mathrm{T}$.

Proof. By Lemma 3.1 and the pushout property .

It is not difficult to translate our graph language to the underlying first-order predicate language. It suffices to express the semantics of the graph language (in 3.1) by formulas.

\section{Graph Calculus}

We now introduce our graph calculus, with conversion and expansion rules. We employ $R^{\star}$ for the reflexive-transitive closure of a binary relation $R$ on a set, as usual.

Our conversion and expansion rules will transform an expression to an equivalent one. Thus, one can apply such a rule in any context. For instance, we will have a rule converting $\perp$ to the empty graph \{\} ; so, we can apply it to convert $\bar{\perp}$ to $\overline{\{\}}$ and $S+\perp / \lambda$ to $S+\{\} / \lambda$, for any slice $S$. Also, we can identify a singleton graph with its slice (cf. 3.1): if $S \triangleright F$ then $\{S\} \triangleright F$ and if $E \triangleright T$ then $E \triangleright\{T\}$.

\subsection{Conversion}

We now introduce the basic objects and the conversion rules.

The basic objects are defined (by mutual recursion) as follows. The basic expressions are the predicate symbols, other than $\doteq$, and $\overline{\mathrm{T}}$, where $\mathrm{T}$ is a basic slice (see below). An $\operatorname{arc} \mathrm{E} / \mathrm{v}$ is basic iff $\mathrm{E}$ is a basic expression. A sketch is basic iff all its arcs are basic. A slice is basic iff its underlying draft is a basic sketch. A graph is basic iff its slices are all basic. For instance, the drafts $D^{\prime}$ and $D^{\prime \prime}$, of Example 3.1 and D, of Example 3.2, (in 3.2) are basic, whereas those in Examples 2.1, 2.2 and 2.3 are not basic.

The conversion rules will transform an expression to an equivalent basic graph.

The formula rules will come from some equivalences between formulas and expressions We now illustrate some of these equivalences. For a 1-ary predicate $\mathrm{p}$, formula $\mathrm{p}(\mathrm{v})$ is equivalent to the 1-ary slice $\langle\{v\},\{p / v\}: v\rangle$, thus $\neg \mathrm{p}(\mathrm{v})$ is equivalent to the 1-ary expression $\mathrm{p}(\mathrm{v})$. Now, consider formulas $r(u, v)$ and $s(v, w)$. For the conjunction $r(u, v) \wedge s(v, w)$, we have a 3-ary slice $S$ equivalent to it, namely the slice $S=\langle N, A: u v w\rangle$, with sets $N=\{u, v, w\}$ and $A=\{r(u, v) / u v, s(v, w) / v w\}$. For the disjunction $\mathrm{r}(\mathrm{u}, \mathrm{v}) \vee \mathrm{s}(\mathrm{v}, \mathrm{w})$ we have a 3-ary graph $\mathrm{G}$ such that $\mathrm{r}(\mathrm{u}, \mathrm{v}) \vee \mathrm{s}(\mathrm{v}, \mathrm{w}) \equiv \mathrm{G}$, namely the graph $\mathrm{G}$ with 2 slices: $\langle\{\mathrm{u}, \mathrm{v}, \mathrm{w}\},\{\mathrm{r}(\mathrm{u}, \mathrm{v}) / \mathrm{uv}\}: \mathrm{uvw}\rangle$ and $\langle\{\mathrm{u}, \mathrm{v}, \mathrm{w}\},\{\mathrm{s}(\mathrm{v}, \mathrm{w}) / \mathrm{vw}\}: \mathrm{uvw}\rangle$. Also, as the conditional formula $\mathrm{r}(\mathrm{u}, \mathrm{v}) \rightarrow \mathrm{s}(\mathrm{v}, \mathrm{w})$ is logically equivalent to $\neg \mathrm{r}(\mathrm{u}, \mathrm{v}) \vee \mathrm{s}(\mathrm{v}, \mathrm{w})$, it is equivalent to the 3-ary graph $\{\langle\{\mathrm{u}, \mathrm{v}, \mathrm{w}\},\{\overline{\mathrm{r}(\mathrm{u}, \mathrm{v})} / \mathrm{uv}\}: \mathrm{uvw}\rangle,\langle\{\mathrm{u}, \mathrm{v}, \mathrm{w}\},\{\mathrm{s}(\mathrm{v}, \mathrm{w}) / \mathrm{vw}\}: \mathrm{uvw}\rangle\}$. The existential formula $\exists \mathrm{yt}(\mathrm{u}, \mathrm{y}, \mathrm{w})$ is equivalent to the 2-ary slice $\langle\{\mathrm{u}, \mathrm{v}, \mathrm{w}\},\{\mathrm{t}(\mathrm{u}, \mathrm{v}, \mathrm{w}) / \mathrm{uvw}\}: \mathrm{uw}\rangle$. Also, as the universal formula $\forall \mathrm{yt}(\mathrm{u}, \mathrm{y}, \mathrm{w})$ is logically equivalent to $\neg \exists \mathrm{y} \neg \mathrm{t}(\mathrm{u}, \mathrm{y}, \mathrm{w})$, it is equivalent to the 2-ary expression $\overline{\langle\{\mathrm{u}, \mathrm{v}, \mathrm{w}\},\{\overline{\mathrm{t}(\mathrm{u}, \mathrm{v}, \mathrm{w})} / \mathrm{uvw}\}: \mathrm{uw}\rangle}$.

The formula rules are the following 8 conversion rules eliminating formulas.

( $\alpha$ ) For an atomic formula $\mathrm{p}(\mathrm{w}): \mathrm{p}(\mathrm{w}) \triangleright\langle\underline{\mathrm{w}},\{\mathrm{p} / \mathrm{w}\}: \mathrm{w}\rangle$. So, we replace $\mathrm{u} \doteq \mathrm{v}, \mathrm{r}(\mathrm{u}, \mathrm{v})$ and $\mathrm{t}(\mathrm{u}, \mathrm{v}, \mathrm{v})$ by

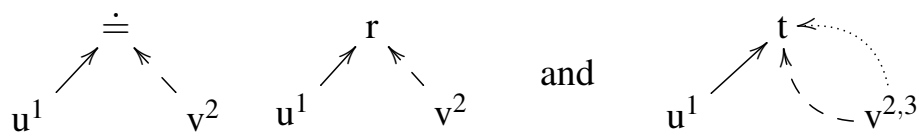


( $\perp) \perp \triangleright\{\}$, i. e. we replace 0 -ary formula $\perp$ by the empty graph.

( $\neg) \neg \varphi \triangleright \bar{\varphi}$. So, we replace $\neg(\mathrm{r}(\mathrm{u}, \mathrm{v}) \rightarrow \mathrm{s}(\mathrm{v}, \mathrm{w}))$ by the 3-ary expression $\overline{\mathrm{r}(\mathrm{u}, \mathrm{v}) \rightarrow \mathrm{s}(\mathrm{v}, \mathrm{w})}$.

- Given formulas $\psi$ and $\theta$, with $\mathrm{u}:=\mathrm{NF}[\psi]$ and $\mathrm{v}:=\mathrm{NF}[\theta]$, set $\mathrm{w}:=\mathrm{u} \cup \mathrm{v}$.

$(\wedge) \psi \wedge \theta \triangleright\langle\mathrm{w},\{\psi / \overrightarrow{\mathrm{u}}, \theta / \overrightarrow{\mathrm{v}}\}: \overrightarrow{\mathrm{w}}\rangle$. Thus, we can replace formula $\mathrm{r}(\mathrm{u}, \mathrm{v}) \wedge \mathrm{s}(\mathrm{v}, \mathrm{v})$ by the 2-ary slice $\langle\{\mathrm{u}, \mathrm{v}\},\{\mathrm{r}(\mathrm{u}, \mathrm{v}) / \mathrm{uv}, \mathrm{s}(\mathrm{v}, \mathrm{v}) / \mathrm{v}\}: \mathrm{uv}\rangle$, which we can represent as:

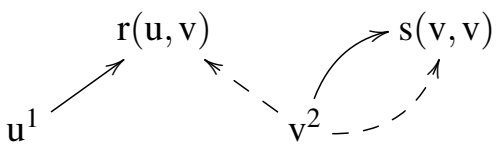

( $\vee) \psi \forall \nabla \triangleright\{\langle\mathrm{w},\{\psi / \overrightarrow{\mathrm{u}}\}: \overrightarrow{\mathrm{w}}\rangle,\langle\mathrm{w},\{\theta / \overrightarrow{\mathrm{v}}\}: \overrightarrow{\mathrm{w}}\rangle\}$. So, we can replace formula $\mathrm{r}(\mathrm{u}, \mathrm{v}) \vee \mathrm{s}(\mathrm{v}, \mathrm{v})$ by the 2-ary $\operatorname{graph}\left\{\begin{array}{c}\langle\{\mathrm{u}, \mathrm{v}\},\{\mathrm{r}(\mathrm{u}, \mathrm{v}) / \mathrm{uv}\}: \mathrm{u} v\rangle \\ \langle\{\mathrm{u}, \mathrm{v}\}, \mathrm{s}(\mathrm{v}, \mathrm{v}) / \mathrm{v}\}: \mathrm{u} v\rangle\end{array}\right\} 10$

$(\rightarrow) \psi \rightarrow \theta \triangleright\langle\mathrm{w},\{\bar{\psi} / \overrightarrow{\mathrm{u}}, \theta / \overrightarrow{\mathrm{v}}\}: \overrightarrow{\mathrm{w}}\rangle$. So, we can replace formula $\mathrm{p}(\mathrm{u}) \rightarrow \mathrm{r}(\mathrm{v}, \mathrm{w})$ by the 3-ary graph

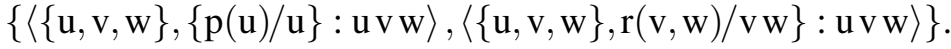

- Given a formula $\varphi$ and a set $\mathrm{v}$ of names, set $\mathrm{u}:=\mathrm{w} \backslash \mathrm{v}$, where $\mathrm{w}:=\operatorname{NF}[\varphi]$.

$\left(\exists^{*}\right)$ For formula $\exists^{*} \mathrm{x} \varphi[\mathrm{v} / \mathrm{x}], \exists^{*} \mathrm{x} \varphi[\mathrm{v} / \mathrm{x}] \triangleright\langle\mathrm{w},\{\varphi / \overrightarrow{\mathrm{w}}\}$ : $\overrightarrow{\mathrm{u}}\rangle$. Thus, we can replace $\exists \mathrm{y} \exists \mathrm{zt}(\mathrm{u}, \mathrm{y}, \mathrm{z})$ by the single-arc 1-ary slice $\langle\{\mathrm{u}, \mathrm{v}, \mathrm{w}\},\{\mathrm{t}(\mathrm{u}, \mathrm{v}, \mathrm{w}) / \mathrm{u} v \mathrm{w}\}: \mathrm{u}\rangle$, which we can represent as:

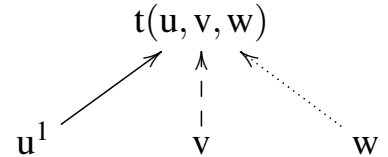

$\left(\forall^{*}\right)$ For formula $\forall^{*} \mathrm{x} \varphi[\mathrm{v} / \mathrm{x}], \forall^{*} \mathrm{x} \varphi[\mathrm{v} / \mathrm{x}] \triangleright \overline{\langle\mathrm{w},\{\bar{\varphi} / \overrightarrow{\mathrm{w}}\}: \overrightarrow{\mathrm{u}}\rangle}$. So, can we replace $\forall \mathrm{y} \forall \mathrm{zt}(\mathrm{u}, \mathrm{y}, \mathrm{z})$ by the 1-ary expression $\overline{\langle\{\mathrm{u}, \mathrm{v}, \mathrm{w}\},\{\overline{\mathrm{t}(\mathrm{u}, \mathrm{v}, \mathrm{w})} / \mathrm{uvw}\}: \mathrm{u}\rangle}$, which we can represent as:

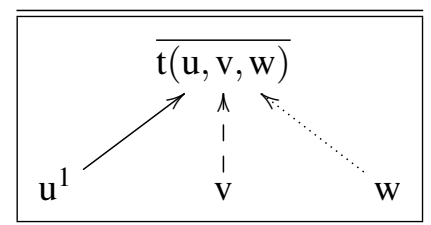

Example 4.1. Consider a formula $\varphi$ with list of names $\langle\mathrm{u}, \mathrm{v}, \mathrm{w}\rangle$, noted $\varphi(\mathrm{u}, \mathrm{v}, \mathrm{w})$.

For the formula $\exists \mathrm{y} \forall \mathrm{z} \varphi(\mathrm{u}, \mathrm{y}, \mathrm{z})$, we have the conversions:

$$
\exists \mathrm{y} \forall \mathrm{z} \varphi(\mathrm{u}, \mathrm{y}, \mathrm{z}) \stackrel{\left(\exists^{*}\right)}{\triangleright}\left\langle\{\mathrm{u}, \mathrm{v}\},\left\{\frac{\forall \mathrm{z} \varphi(\mathrm{u}, \mathrm{v}, \mathrm{z})}{\mathrm{uv}}\right\}: \mathrm{u}\right\rangle \stackrel{\left(\forall^{*}\right)}{\triangleright}\left\langle\{\mathrm{u}, \mathrm{v}\},\left\{\frac{\overline{\langle\{\mathrm{u}, \mathrm{v}, \mathrm{w}\},\{\bar{\varphi} / \mathrm{uvw}\}: \mathrm{uv}\rangle}}{\mathrm{uv}}\right\}: \mathrm{u}\right\rangle
$$

For the formula $\forall \mathrm{y} \exists \mathrm{z} \varphi(\mathrm{u}, \mathrm{y}, \mathrm{z})$, we have the conversions:

$$
\forall \mathrm{y} \exists \boldsymbol{z} \varphi(\mathrm{u}, \mathrm{y}, \mathrm{z}) \stackrel{\left(\forall^{*}\right)}{\triangleright}\left\langle\left\{\{\mathrm{u}, \mathrm{v}\},\left\{\overline{\left.\left.\frac{\exists \mathrm{z} \varphi(\mathrm{u}, \mathrm{y}, \mathrm{z})}{\mathrm{uv}}\right\}: \mathrm{u}\right\rangle} \stackrel{\left(\exists^{*}\right)}{\triangleright} \overline{\left\langle\{\mathrm{u}, \mathrm{v}\},\left\{\frac{\overline{\langle\{\mathrm{u}, \mathrm{v}, \mathrm{w}\},\{\varphi / \mathrm{uvw}\}: \mathrm{uv}\rangle}}{\mathrm{uv}}\right\}: \mathrm{u}\right\rangle}\right.\right.\right.
$$

\footnotetext{
${ }^{10}$ This graph can be represented as follows:

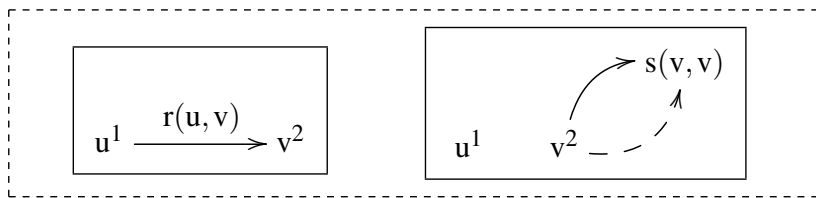


By applying the 8 formula rules in any context, one can transform an expression to an equivalent expression without connectives or quantifiers.

The equality rule is the following conversion rule, eliminating expression $\doteq$.

$(\doteq) \doteq \triangleright\langle\{\mathrm{u}\}, \emptyset:\langle\mathrm{u}, \mathrm{u}\rangle\rangle$, where $\mathrm{u} \in \mathrm{Nm}$. So, we can replace slice $\langle\{\mathrm{u}, \mathrm{v}, \mathrm{w}\},\{\mathrm{r} / \mathrm{uv}, \doteq / \mathrm{vw}, \mathrm{s} / \mathrm{u} w\}: \mathrm{vw}\rangle$ by the slice $\left\langle\{\mathrm{v}, \mathrm{w}\},\left\{\mathrm{r} / \mathrm{uv}, \frac{\langle\{\mathrm{u}\}, \emptyset:\langle\mathrm{u}, \mathrm{u}\rangle\rangle}{\mathrm{vw}}, \mathrm{s} / \mathrm{uw}\right\}: \mathrm{vw}\right\rangle$.

By using these 9 rules, one can eliminate logical symbols and predicates, but arcs whose expressions are slices or graphs, perhaps complemented, may appear. For instance, this happens with $\mathrm{v} \doteq \mathrm{w}$ and $\exists \mathrm{y}(\mathrm{r}(\mathrm{u}, \mathrm{y}) \wedge \mathrm{s}(\mathrm{y}, \mathrm{w}))$. The following rules will address these cases.

The complementation rules are the following 2 conversion rules, moving - inside.

(U) For an $n$-ary graph $\mathrm{H}: \overline{\mathrm{H}} \triangleright\langle\underline{\mathrm{w}},\{\overline{\mathrm{T}} / \mathrm{w}: \mathrm{T} \in \mathrm{H}\}: \mathrm{w}\rangle$, where $\mathrm{w}$ is a list of $n$ distinct names. So, we can replace the complemented 1-ary graph $\overline{\{\mathrm{S}, \mathrm{T}\}}$ by the slice $\langle\{\mathrm{v}\},\{\overline{\mathrm{S}} / \mathrm{v}, \overline{\mathrm{T}} / \mathrm{v}\}: \mathrm{v}\rangle$.

(=) $\overline{\overline{\mathrm{E}}} \triangleright$ E, i. e. eliminate double complementation.

By applying these 2 complementation rules in any context, one can eliminate arcs whose expressions are complemented graphs.

The structural rules are the following 3 conversion rules.

$(\stackrel{\cup}{\longrightarrow}) \mathrm{S}+\mathrm{H} / \mathrm{v} \triangleright\{\mathrm{S}+\mathrm{T} / \mathrm{v}: \mathrm{T} \in \mathrm{H}\}$, i. e. replace addition of graph arc by alternative addition of its slice arcs. So, we replace slice $S+\left\{\mathrm{T}^{\prime}, \mathrm{T}^{\prime \prime}\right\} / \mathrm{u}$ by the graph $\left\{\mathrm{S}+\mathrm{T}^{\prime} / \mathrm{u}, \mathrm{S}+\mathrm{T}^{\prime \prime} / \mathrm{u}\right\}$.

$(\stackrel{\mathrm{T}}{\rightarrow}) \mathrm{S}+\mathrm{T} / \mathrm{v} \triangleright \mathrm{S}^{\mathrm{v}} \mathrm{T}$, i. e. replace addition of slice arc by glued slice.

( $\uparrow$ ) For an $n$-ary expression $\mathrm{E}: \mathrm{E} \triangleright\langle\underline{\mathrm{w}},\{\mathrm{E} / \mathrm{w}\}: \mathrm{w}\rangle$, where $\mathrm{w}$ is a list of $n$ distinct names. So, for $\mathrm{r} \in \operatorname{Pr}_{2}$, we can replace 2-ary expression $r$ by the 2-ary slice $\left\langle\left\{u_{1}, u_{2}\right\},\left\{r / u_{1} u_{2}\right\}: u_{1} u_{2}\right\rangle$.

By means of rules $(\stackrel{\cup}{\longrightarrow})$ and $(\stackrel{T}{\rightarrow})$, one can eliminate arcs whose expressions are graphs or slices. Rule $(\uparrow)$ converts expressions to slices and serves to eliminate $\overline{\mathrm{p}}: \overline{\mathrm{p}} \stackrel{(\uparrow)}{\triangleright} \overline{\left\langle\underline{\mathrm{u}^{n}},\left\{\mathrm{p} / \mathrm{u}^{n}\right\}: \mathrm{u}^{n}\right\rangle}$, for $\mathrm{p} \in \operatorname{Pr}_{n}$.

Example 4.2. Consider the formula $\mathrm{r}(\mathrm{v}, \mathrm{w})$. We proceed much as in Example 4.1.

Formula $\exists \mathrm{y} \forall \mathrm{zr}(\mathrm{y}, \mathrm{z})$ converts to the 0 -ary slice $\mathrm{S}=\left\langle\{\mathrm{v}\},\left\{\frac{\overline{\langle\{\mathrm{v}, \mathrm{w}\},\{\overline{\mathrm{r}(\mathrm{v}, \mathrm{w})} / \mathrm{vw}\}: \mathrm{v}\rangle}}{\mathrm{v}}\right\}: \lambda\right\rangle$.

This slice $S$ is not basic, but it can be converted to a basic slice by $(\alpha)$ as follows:

$$
\left\langle\{\mathrm{v}\},\left\{\frac{\overline{\left.\langle\mathrm{v}, \mathrm{w}\},\left\{\frac{\overline{\mathrm{r}(\mathrm{v}, \mathrm{w})}}{\mathrm{vw}}\right\}: \mathrm{v}\right\rangle}}{\mathrm{v}}\right\}: \lambda\right\rangle \stackrel{(\alpha)}{\triangleright}\left\langle\{\mathrm{v}\},\left\{\frac{\overline{\left\langle\{\mathrm{v}, \mathrm{w}\},\left\{\frac{\overline{\left\langle\{\mathrm{v}, \mathrm{w}\},\left\{\frac{\mathrm{r}}{\mathrm{vw}}\right\}: \mathrm{vw}\right\rangle}}{\mathrm{vw}}\right\}: \mathrm{v}\right\rangle}}{\mathrm{v}}\right\}: \lambda\right\rangle
$$

Formula $\forall \mathrm{y} \exists \mathrm{z} \mathrm{r}(\mathrm{y}, \mathrm{z})$ converts to the 0-ary expression $\mathrm{E}=\overline{\left\langle\{\mathrm{v}\},\left\{\frac{\overline{\langle\{\mathrm{v}, \mathrm{w}\},\{\mathrm{r}(\mathrm{v}, \mathrm{w}) / \mathrm{vw}\}: \mathrm{v}\rangle}}{\mathrm{v}}\right\}: \lambda\right\rangle}$.

This expression $\mathrm{E}$ is not basic, but it can be converted to a basic expression $\mathrm{F}$ by $(\alpha)$ as follows:

$$
\overline{\left\langle\{\mathrm{v}\},\left\{\frac{\overline{\langle\{\mathrm{v}, \mathrm{w}\},\{\mathrm{r}(\mathrm{v}, \mathrm{w}) / \mathrm{vw}\}: \mathrm{v}\rangle}}{\mathrm{v}}\right\}: \lambda\right\rangle \stackrel{(\alpha)}{\triangleright}\left\langle\{\mathrm{v}\},\left\{\frac{\overline{\left\langle\{\mathrm{v}, \mathrm{w}\},\left\{\left\langle\{\mathrm{v}, \mathrm{w}\},\left\{\frac{\mathrm{r}}{\mathrm{vw}}\right\}: \mathrm{vw}\right\rangle / \mathrm{vw}\right\}: \mathrm{v}\right\rangle}}{\mathrm{v}}\right\}: \lambda\right\rangle}
$$

Expression $\mathrm{F}$ can be converted to a basic 0-ary slice by $(\uparrow)$. 
Rule $(\stackrel{\mathrm{T}}{\rightarrow})$ gives some useful derived rules about arc addition, which we can use to shorten conversions (such shortenings were used in the examples of Section 2). We can replace addition of: a graph arc by gluing the graph $\left((\stackrel{\mathrm{H}}{\longrightarrow}): \mathrm{S}+\mathrm{H} / \mathrm{v}^{\star}{ }^{\star} \mathrm{S}^{\mathrm{v}} \mathrm{H}\right)$, a complemented-graph arc by addition of parallel complemented-slice arcs $\left(\mathrm{S}+\overline{\mathrm{H}} / \mathrm{v} \triangleright^{\star} \mathrm{S}+\{\overline{\mathrm{T}} / \mathrm{v}: \mathrm{T} \in \mathrm{H}\}\right)$ and an equality arc by node renaming $\left(\mathrm{S}+\doteq / \mathrm{uv} \triangleright^{\star} \mathrm{S}[\mathrm{u} / \mathrm{v}], \mathrm{S}+\doteq / \mathrm{uv} \triangleright^{\star} \mathrm{S}[\mathrm{v} / \mathrm{u}]\right)$.

We can also replace $n$ conjunctions and disjunctions by slices and graphs, respectively 11

Example 4.3. Consider the formula $\mathrm{s}\left(\mathrm{v}^{\prime}, \mathrm{w}^{\prime}\right) \wedge \exists \mathrm{x}\left[\mathrm{r}\left(\mathrm{v}^{\prime}, \mathrm{x}\right) \wedge \neg \exists \mathrm{y}\left(\mathrm{r}(\mathrm{x}, \mathrm{y}) \wedge \mathrm{s}\left(\mathrm{y}, \mathrm{w}^{\prime}\right)\right)\right]$. This expression $\mathrm{E}$ can be converted to the 2-ary slice $\left\langle\mathrm{D}: \mathrm{v}^{\prime} \mathrm{w}^{\prime}\right\rangle$, where $\mathrm{D}$ is the draft of Example 3.2 (in 3.2).

We can convert expressions in a modular way.

Lemma 4.1. If $S \triangleright^{\star} \mathrm{G}$ and $\mathrm{E} \triangleright^{\star} \mathrm{H}$, then $\mathrm{S}+\mathrm{E} / \mathrm{v} \triangleright^{\star} \mathrm{G}^{\mathrm{v}} \mathrm{H}$.

Proof. By $(\stackrel{\mathrm{H}}{\longrightarrow})$ rule: $\mathrm{S}+\mathrm{E} / \mathrm{v} \triangleright^{\star} \mathrm{G}+\mathrm{H} / \mathrm{v}=\{\mathrm{P}+\mathrm{H} / \mathrm{v}: \mathrm{P} \in \mathrm{G}\} \stackrel{(\stackrel{\mathrm{H}}{\triangleright})}{\triangleright^{\circ}}\left\{\mathrm{P}^{\mathrm{v}} \mathrm{H}: \mathrm{P} \in \mathrm{G}\right\}=\mathrm{G}^{\mathrm{v}} \mathrm{H}$.

Thus, one can obtain a basic form for $\mathrm{S}+\mathrm{E} / \mathrm{v}$ from basic forms $\mathrm{S}^{\mathrm{b}}$ and $\mathrm{E}^{\mathrm{b}}$, for $\mathrm{S}$ and $\mathrm{E}$.

Proposition 4.1. Every n-ary expression $\mathrm{E}$ can be effectively converted to a basic n-ary graph $\mathrm{E}^{\mathrm{b}}$.

Proof. By induction on the structure of expressions.

Example 4.4. Given the predicate symbols of Example 3.1 (in 3.2), consider the formula $\psi$ :

$$
\mathrm{q}(\mathrm{v}, \mathrm{w}) \wedge \exists \mathrm{z}\left[\mathrm{p}(\mathrm{z}) \wedge \mathrm{r}(\mathrm{v}, \mathrm{z}) \wedge \exists \mathrm{x} \exists \mathrm{y} \exists \mathrm{y}^{\prime}(\mathrm{s}(\mathrm{v}, \mathrm{x}) \wedge \mathrm{t}(\mathrm{x}, \mathrm{w}) \wedge \mathrm{a}(\mathrm{x}, \mathrm{y}) \wedge \mathrm{b}(\mathrm{y}, \mathrm{w}))\right] .
$$

Consider also the formula $\theta:=\exists^{3} \mathrm{x}_{1} \mathrm{x}_{2} \mathrm{x}_{3} \exists \mathrm{y}^{\prime} \exists^{2} \mathrm{y}_{1} \mathrm{y}_{2} \exists \mathrm{z}^{\prime} \exists^{2} \mathrm{z}_{1}, \mathrm{z}_{2} \chi$, where $\chi$ is as follows:

$$
\mathrm{p}\left(\mathrm{z}^{\prime}\right) \wedge \mathrm{s}\left(\mathrm{v}_{2}, \mathrm{x}_{3}\right) \wedge \mathrm{t}\left(\mathrm{x}_{2}, \mathrm{z}_{1}\right) \wedge\left(\begin{array}{c}
\mathrm{q}\left(\mathrm{y}_{1}, \mathrm{z}_{1}\right) \\
\wedge \\
\mathrm{q}\left(\mathrm{y}_{2}, \mathrm{z}_{2}\right)
\end{array}\right) \wedge\left(\begin{array}{c}
\mathrm{a}\left(\mathrm{x}_{1}, \mathrm{v}^{\prime}\right) \\
\wedge \\
\mathrm{a}\left(\mathrm{x}_{2}, \mathrm{v}^{\prime}\right)
\end{array}\right) \wedge\left(\begin{array}{c}
\mathrm{r}\left(\mathrm{v}, \mathrm{z}^{\prime}\right) \\
\wedge \\
\mathrm{r}\left(\mathrm{y}_{1}, \mathrm{z}^{\prime}\right) \\
\wedge \\
\mathrm{r}\left(\mathrm{y}_{2}, \mathrm{z}^{\prime}\right)
\end{array}\right) \wedge\left(\begin{array}{c}
\mathrm{b}\left(\mathrm{y}^{\prime}, \mathrm{w}\right) \\
\wedge \\
\mathrm{b}\left(\mathrm{y}^{\prime}, \mathrm{z}_{1}\right) \\
\wedge \\
\mathrm{b}\left(\mathrm{y}^{\prime}, \mathrm{z}_{2}\right)
\end{array}\right) .
$$

Now, form the difference slice $\operatorname{DS}[\{\mathrm{a}[\psi]\} \angle \mathrm{a}[\theta]]=\langle\{\mathrm{v}, \mathrm{w}\},\{\psi / \mathrm{vw}, \bar{\theta} / \mathrm{v} \mathrm{w}: \lambda\}\rangle$. Expressions $\psi$ and $\theta$ can be respectively converted to the 2 -ary slices $\mathrm{S}=\left\langle\mathrm{D}^{\prime}:\langle\mathrm{v}, \mathrm{w}\rangle\right\rangle$ and $\mathrm{T}=\left\langle\mathrm{D}^{\prime \prime}:\langle\mathrm{v}, \mathrm{w}\rangle\right\rangle$, where $\mathrm{D}^{\prime}$ and $\mathrm{D}^{\prime \prime}$ are the drafts of Example 3.1 Thus, we have $\mathrm{DS}[\{\mathrm{a}[\psi]\} \angle \mathrm{a}[\theta]] \triangleright^{\star}\langle\{\mathrm{v}, \mathrm{w}\},\{\mathrm{S} / \mathrm{vw}, \overline{\mathrm{T}} / \mathrm{vw}: \lambda\}\rangle$. Now, we can see that $\langle\{\mathrm{v}, \mathrm{w}\},\{\mathrm{S} / \mathrm{vw}, \overline{\mathrm{T}} / \mathrm{vw}: \lambda\}\rangle \stackrel{(\stackrel{\mathrm{T}}{)})}{\triangleright}\langle\underline{\mathrm{S}}+\overline{\mathrm{T}} / \mathrm{vw}: \lambda\rangle .12$ Hence $\mathrm{DS}[\{\mathrm{a}[\psi]\} \angle \mathrm{a}[\theta]] \triangleright^{\star}\langle\underline{\mathrm{S}}+\overline{\mathrm{T}} / \mathrm{vw}: \lambda\rangle$.

\subsection{Derivations}

We now introduce the remaining rule and finish the presentation of our calculus.

First, let us review Examples 4.3 and 4.4 (in 4.1). Formula E of Example 4.3 converts to the 2-ary slice $\left\langle\mathrm{D}: \mathrm{v}^{\prime} \mathrm{w}^{\prime}\right\rangle$, which was seen to be zero in Example 3.2 (in 3.2). Thus, formula $\mathrm{E}$ is unsatisfiable. Now, consider formulas $\psi$ and $\theta$ of Example 4.4 , where we have seen that $\mathrm{DS}[\{\mathrm{a}[\psi]\} \angle \mathrm{a}[\theta]] \triangleright^{\star}\langle\underline{\mathrm{S}}+\overline{\mathrm{T}} / \mathrm{vw}: \lambda\rangle$. Now, Example 3.1 (in 3.2) shows a morphism $\eta: \underline{I} \rightarrow \underline{\mathrm{S}}$, with $\hat{\mathrm{t}}^{\eta}=\left\langle\mathrm{v}^{\eta}, \mathrm{w}^{\eta}\right\rangle=\langle\mathrm{v}, \mathrm{w}\rangle=\hat{\mathrm{s}}$. Thus, draft $\underline{\mathrm{S}}+\overline{\mathrm{T}} / \mathrm{v} w$ is zero, whence, slice $\mathrm{DS}[\{\mathrm{a}[\psi]\} \angle \mathrm{a}[\theta]]$ is null. Therefore, we can conclude that $\psi \models \theta$.

\footnotetext{
${ }^{11}$ For instance, with 3 formulas, we have $\mathrm{r}(\mathrm{u}, \mathrm{v}) \wedge \mathrm{s}(\mathrm{v}, \mathrm{w}) \wedge \mathrm{p}(\mathrm{w}) \triangleright^{\star}\langle\{\mathrm{u}, \mathrm{v}, \mathrm{w}\},\{\mathrm{r}(\mathrm{u}, \mathrm{v}) / \mathrm{uv}, \mathrm{s}(\mathrm{v}, \mathrm{w}) / \mathrm{vw}, \mathrm{p}(\mathrm{w}) / \mathrm{w}\}: \mathrm{uvw}\rangle$ and $\left.\left.\mathrm{r}(\mathrm{u}, \mathrm{v}) \vee \mathrm{s}(\mathrm{v}, \mathrm{w}) \vee \mathrm{p}(\mathrm{w}) \triangleright^{\star}\{\langle\{\mathrm{u}, \mathrm{v}, \mathrm{w}\},\{\mathrm{r}(\mathrm{u}, \mathrm{v}) / \mathrm{uv}\}: \mathrm{uvw}\rangle,\langle\{\mathrm{u}, \mathrm{v}, \mathrm{w}\}, \mathrm{s}(\mathrm{v}, \mathrm{w}) / \mathrm{vw}\}: \mathrm{uvw}\rangle\langle\{\mathrm{u}, \mathrm{v}, \mathrm{w}\},\{\mathrm{p}(\mathrm{w}) / \mathrm{w}\}: \mathrm{uvw}\rangle\right\}.\right)$.

${ }^{12}$ Indeed: $\langle\{\mathrm{v}, \mathrm{w}\},\{\mathrm{S} / \mathrm{vw}, \overline{\mathrm{T}} / \mathrm{vw}: \lambda\}\rangle=\langle\{\mathrm{v}, \mathrm{w}\},\{\overline{\mathrm{T}} / \mathrm{vw}: \lambda\}\rangle+\mathrm{S} / \mathrm{vw} \stackrel{(\stackrel{\mathrm{T}}{\vec{D}})}{\sim}\langle\{\mathrm{v}, \mathrm{w}\},\{\overline{\mathrm{T}} / \mathrm{vw}: \lambda\}\rangle^{\langle\mathrm{v}, \mathrm{w}\rangle} \mathrm{S}=\langle\underline{\mathrm{S}}+\overline{\mathrm{T}} / \mathrm{vw}: \lambda\rangle$.
} 
Example 4.5. To introduce expansion and its usefulness, consider the 3-ary slice S:

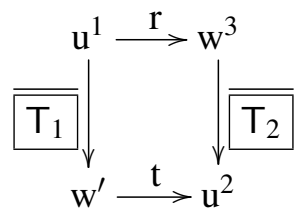

where $\mathrm{T}_{1}:=\mathrm{u}^{1} \stackrel{\mathrm{r}}{\rightarrow} \mathrm{w} \stackrel{\mathrm{s}}{\rightarrow} \mathrm{v}^{2}, \quad \mathrm{~T}_{2}:=\mathrm{u}^{1} \stackrel{\overline{\mathrm{s}}}{\rightarrow} \mathrm{w} \stackrel{\mathrm{t}}{\rightarrow} \mathrm{v}^{2}$.

Slice $\mathrm{S}$ is not zero; but in any model $\mathfrak{M}$, the pair $\left(\mathrm{g}(\mathrm{w}), \mathrm{g}\left(\mathrm{w}^{\prime}\right)\right)$ is either in $[\mathrm{s}]_{\mathfrak{M}}$ or in $[\overline{\mathrm{s}}]_{\mathfrak{M}}$. So, $\mathrm{S}$ is equivalent to the 2-ary graph $\mathrm{G}=\left\{\mathrm{S}_{+}, \mathrm{S}_{-}\right\}$, with slices $\mathrm{S}_{+}$and $\mathrm{S}_{-}$, respectively as follows:
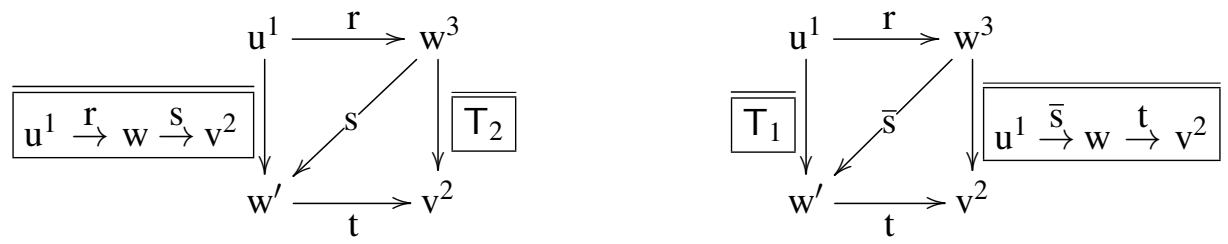

Slices $\mathrm{S}_{+}$and $\mathrm{S}_{-}$are both zero, so graph $\mathrm{G}$ is zero. Thus, $\mathrm{S}$ is a null slice.

The expansion rule will replace a slice by a graph with 2 alternative slices.

$(\triangleleft)$ For an $m$-ary slice $\mathrm{T}$ and $\mathrm{v} \in \mathrm{N}_{\mathrm{S}}{ }^{m}: \mathrm{S} \triangleleft\left\{\mathrm{S}^{\mathrm{v}} \mathrm{T}, \mathrm{S}+\overline{\mathrm{T}} / \mathrm{v}\right\}$.

Note that both $\mathrm{S}^{\mathrm{v}} \mathrm{T}$ and $\mathrm{S}+\overline{\mathrm{T}} / \mathrm{v}$ are basic whenever $\mathrm{S}$ and $\mathrm{T}$ are basic.

Lemma 4.2. For a slice $\mathrm{S}$, an m-ary slice $\mathrm{T}$ and $\mathrm{v} \in \mathrm{Nm}^{m}: \mathrm{S} \equiv\left\{\mathrm{S}^{\mathrm{v}} \mathrm{T}, \mathrm{S}+\overline{\mathrm{T}} / \mathrm{v}\right\}$.

Proof. By Proposition 3.2 (in 3.2), $\mathrm{S}+\mathrm{T} / \mathrm{v} \equiv \mathrm{S}^{\mathrm{v}} \mathrm{T}$, and clearly $\mathrm{S} \equiv\{\mathrm{S}+\mathrm{T} / \mathrm{v}, \mathrm{S}+\mathrm{T} / \mathrm{v}\}$.

A derivation consists of applications of the conversion rules and the expansion rule: $\vdash:=(\triangleright \cup \triangleleft)^{\star}$. A derivation is normal iff applications of conversion rules precede applications of the expansion rule: $E \triangleright^{\star} G \triangleleft^{\star} H$. In practice, as we wish to derive a zero graph, we may erase slices already found to be zero.

Let $\varphi$ be the formula $\mathrm{r}(\mathrm{u}, \mathrm{w}) \wedge \mathrm{t}\left(\mathrm{w}^{\prime}, \mathrm{v}\right) \wedge \neg \exists \mathrm{x}[\mathrm{r}(\mathrm{u}, \mathrm{x}) \wedge \mathrm{s}(\mathrm{x}, \mathrm{v})] \wedge \neg \exists \mathrm{y}[\neg \mathrm{s}(\mathrm{u}, \mathrm{y}) \wedge \mathrm{t}(\mathrm{y}, \mathrm{v})]$. Expression $\mathrm{E}:=\exists \mathrm{x} \varphi\left[\mathrm{w}^{\prime} / \mathrm{x}\right]$ converts to the slice $\mathrm{S}$ of Example 4.5, where it expands to the graph $\mathrm{G}$. We thus have the normal derivation $E \triangleright^{\star} S \triangleleft G$, with $G$ a zero graph. Hence, formula $\varphi$ is unsatisfiable.

\subsection{Soundness and completeness}

We now examine soundness and completeness of our calculus.

Soundness is clear (as $\mathrm{E} \equiv \mathrm{F}$, whenever $\mathrm{E} \vdash \mathrm{F}$ ): if $\mathrm{E} \vdash \mathrm{H}$ and $\mathrm{H}$ is zero, then $\mathrm{E}$ is null. We will show that a converse holds for basic graphs (if $\mathrm{E}^{\mathrm{b}}$ is null then $\mathrm{E}^{\mathrm{b}}$ expands to a zero graph), and we will have completeness of normal derivations: if $\mathrm{E}$ is null, then $\mathrm{E} \triangleright^{\star} \mathrm{E}^{\mathrm{b}} \triangleleft^{\star} \mathrm{H}$, for some zero graph $\mathrm{H}$.

Henceforth, all sketches, drafts, slices and graphs will be basic. We define the following families of slices: the family $Z_{0}$ of zero slices (cf. 3.2); the family $Z_{*}$ of expansivley zero slices: the slices $S$ such that, for some graph $\mathrm{G} \subseteq Z_{0}, S \triangleleft^{\star} \mathrm{G}$; the family $Z_{\infty}$ of not expansively zero slices: the slices outside $Z_{*}$.

The following simple properties of these families will be useful.

Lemma 4.3. For every graph $\mathrm{G}: \mathrm{G} \subseteq Z_{*}$ iff, for some graph $\mathrm{H} \subseteq Z_{0}, \mathrm{G} \triangleleft^{\star} \mathrm{H}$.

Proof. $\left(\Rightarrow\right.$ ) If, for each $\mathrm{S} \in \mathrm{G}, \mathrm{S} \triangleleft^{\star} \mathrm{H}_{\mathrm{S}}$ and $\mathrm{H}_{\mathrm{S}} \subseteq Z_{0}$, then, with $\mathrm{H}:=\bigcup_{\mathrm{S} \in \mathrm{G}} \mathrm{H}_{\mathrm{S}}, \mathrm{G} \triangleleft^{\star} \mathrm{H}$ and $\mathrm{H} \subseteq Z_{0}$. $(\Leftarrow)$ if $\mathrm{G} \triangleleft^{\star} \mathrm{H}$, with $\mathrm{H} \subseteq Z_{0}$, then for each $\mathrm{S} \in \mathrm{G}, \mathrm{S} \triangleleft^{\star} \mathrm{H}_{\mathrm{S}}$, with $\mathrm{H}_{\mathrm{S}} \subseteq \mathrm{H} \subseteq Z_{0}$, whence $\mathrm{S} \in Z_{*}$. 
Lemma 4.4. For every graph $\mathrm{G}: \mathrm{G} \subseteq Z_{*}$ iff, for some graph $\mathrm{H} \subseteq Z_{*}, \mathrm{G} \triangleleft^{\star} \mathrm{H}$.

Proof. By Lemma 4.3 , since $Z_{0} \subseteq Z_{*}$. $\left(\Rightarrow\right.$ ) If $\mathrm{G} \subseteq Z_{*}$, then $\mathrm{G} \triangleleft^{\star} \mathrm{H}$, with $\mathrm{H} \subseteq Z_{0} \subseteq Z_{*}$. $(\Leftarrow)$ If $\mathrm{G} \triangleleft^{\star} \mathrm{H}$, with $\mathrm{H} \subseteq Z_{*}$, then $\mathrm{H} \triangleleft^{\star} \mathrm{H}^{\prime}$, with $\mathrm{H}^{\prime} \subseteq Z_{0}$, whence $\mathrm{G} \triangleleft^{\star} \mathrm{H}^{\prime}$, with $\mathrm{H}^{\prime} \subseteq Z_{*}$.

Corollary 4.1. For $\mathrm{S} \in Z_{\infty}$, m-slice $\mathrm{T}$ and $\mathrm{v} \in \mathrm{N}_{\mathrm{S}}{ }^{m}$ : one of $\mathrm{S}^{\mathrm{v}} \mathrm{T}$ and $\mathrm{S}+\overline{\mathrm{T}} / \mathrm{v}$ is not expansively zero.

Proof. By Lemma 4.4: if $\left\{\mathrm{S}^{\mathrm{v}} \mathrm{T}, \mathrm{S}+\overline{\mathrm{T}} / \mathrm{v}\right\} \subseteq Z_{*}$, then $\mathrm{S} \in Z_{*}$.

We will show that a slice $S \in Z_{\infty}$ has a model $\mathfrak{M}$ with $\left[[S]_{\mathfrak{M}} \neq \emptyset\right.$

Given a slice $\mathrm{S} \in Z_{\infty}$, we can obtain a set of slices $\mathrm{S}_{n}=\left\langle\mathrm{N}_{n}, \mathrm{~A}_{n}: \hat{\mathrm{S}}_{n}\right\rangle$ with $\mathrm{S}_{n} \in Z_{\infty}$, for $n \in \mathbb{N}$, whose underlying drafts are connected by morphisms $\mu_{n}$ from $\underline{S}_{n}$ to $\underline{S}_{n+1}$, which we extend naturally to morphisms $\mu \frac{i}{j}: \underline{\mathrm{S}}_{i} \rightarrow \underline{\mathrm{S}}_{j}$, for $i \leq j$. Consider the co-limit of this draft diagram: sketch $\Sigma=\langle\mathrm{N}, \mathrm{A}\rangle$ with morphisms $v_{n}: \underline{\mathrm{S}}_{n} \rightarrow \Sigma$ (cf. 3.2). We use this co-limit sketch $\Sigma$ to define a natural model $\mathfrak{M}$ with $M:=\mathrm{N}$, and $\mathrm{p}^{\mathfrak{M}}:=\left\{\mathrm{v} \in M^{n}: \mathrm{p} / \mathrm{v} \in \mathrm{A}\right\}$, for $\mathrm{p} \in \operatorname{Pr}_{n}$.

By construction, the co-limit sketch $\Sigma$ is saturated in the following sense: given any $m$-ary slice $T=\langle\underline{T}: \hat{\mathrm{t}}\rangle$ and $\mathrm{w} \in \mathrm{N}^{m}$, we have $\operatorname{arc} \overline{\mathrm{T}} / \mathrm{w} \in \mathrm{A}$ or there is a morphism $\eta: \underline{I} \rightarrow \Sigma$ with $\hat{\mathrm{t}}^{\eta}=\mathrm{w}$.

We can establish that satisfying assignments are morphisms.

Lemma 4.5. Given a draft $\mathrm{D}$ and $\mathrm{g}: \mathrm{N}_{\mathrm{D}} \rightarrow M, \mathrm{~g}: \mathrm{D} \rightarrow \mathfrak{M}$ iff $\mathrm{g}: \mathrm{D} \rightarrow \Sigma$.

Proof. By structural induction (on the total number of complemented slice arcs occurring in D).

Finally, since $v_{0}: \underline{\mathrm{S}} \rightarrow \Sigma$, we have $v_{0}\left(\hat{\mathrm{s}}_{0}\right) \in[[S]]_{\mathfrak{M}} \neq \emptyset$.

Therefore, if $\mathrm{G} \nsubseteq Z_{*}$, then $\mathrm{G}$ is not null.

Theorem 4.1. Consider an n-ary expression $\mathrm{E}$.

$(\vdash)$ If $\mathrm{E} \vdash \mathrm{H}$ and $\mathrm{H}$ is zero, then $\mathrm{E}$ is null.

$\left(\triangleright^{\star} ; \triangleleft^{\star}\right)$ If $\mathrm{E}$ is null, then $\mathrm{E} \triangleright^{\star} \mathrm{E}^{\mathrm{b}} \triangleleft^{\star} \mathrm{H}$, for some zero n-ary graph $\mathrm{H}$.

\section{Conclusion}

We now present some concluding remarks, including comparison with related works.

We have presented a refutation graph calculus for classical first-order predicate logic. This sound and complete calculus reduces logical consequence to establishing that a constructed graph is null, i. e. has empty extension in every model. Our calculus uses formulas directly and can represent them by arcs.

We have a simple strategy for establishing that a graph $\mathrm{G}$ is null: first convert $\mathrm{G}$ to basic form, then apply repeatedly the expansion rule, erasing slices found to be zero, which is decidable (cf. 3.2), trying to obtain the empty graph. Conversion to basic form, though tedious, can be automated (cf. 4.1); some ingenuity may be required in selecting which slice of a graph to expand and how to do it (cf.4.2), but the embedded slices can provide a finer control. In fact, a (human-guided) system may be envisaged.

The idea of using graphical representations for logic appears in several works.

Girard's proof nets have been applied to classical logic [10], where sequent proofs are translated to proof nets. In our case, however, the (macroscopic) structure of normal derivations is rather simple: first conversions, then expansion (cf. 4.2).

Graph rewriting motivates a graphical representation of first-order predicate logic. For the binary fragment (with $\doteq$ ), a representation of formulas by graph predicates has been obtained by Rensink [9]: a correspondence between sets of graph predicates with depth up to $n$ and a hierarchy $\exists(\neg \exists)^{n}$. There are 
close similarities between some concepts (our sketches are his graphs), but his graph predicates involve morphisms (even though they may be reminiscent of our arcs).

Our approach does resemble Peirce's ideas [11] as formulated by Dau [4]. In our representation, we use names only for referring to them in the meta-language: if we erase these names, we obtain a representation quite close to the Peirce's ones (cf. Example 4.2 in 4.1). Besides our refutation approach with normal derivations, there are some differences: we allow formulas directly in the graphs (and need conversion rules), rather than pre-processing diagrams for them; Peirce considers the fragment $\neg, \wedge$ and $\exists$, whereas we use graphs to cope with $\vee$, which seems to lead to less cumbersome representations; we handle $\doteq$, first as a 2-ary predicate and then as a special one, whereas Peirce represents it directly by identity lines, leading to more compact diagrams. So, there appear to be advantages and disadvantages on both sides.

Some further work on our calculus would be: add function symbols (for this purpose, some ideas used for structured nodes [6] seem promising); provide a detailed comparison between it and [9] (such a comparison between Peirce's and Rensink's approaches is reported difficult [9], p. 333); develop a "middle-ground" between our approach and Dau's [4], with the best features from each one.

\section{References}

[1] T. Barkowsky (2010): Diagrams in the mind: visual or spatial?. In A. K. Goel, M. Jamnik \& N. H. Narayanan, editors: LNAI, Series 6170, p. 1, Springer-Verlag, Berlin, doi:10.1007/978-3-540-92687-0.

[2] S. Curtis \& G. Lowe (1995): A graphical calculus. In B. Moller, editor: Mathematics of Program Construction LNCS Series 947, Springer-Verlag, Berlin, pp. 214-231, doi $10.1007 / 3-540-60117-1-12$

[3] S. Curtis \& G. Lowe (1996): Proofs with graphs. In R. Backhouse, editor: Science of Computer Programming, Elsevier, volume (26), pp. 197-216, doi:10.1016/0167-6423(95)00025-9.

[4] F. Dau (2006): Mathematical logic with diagrams, based on the existential graphs of Peirce, Habil. thesis, TU Dresden, 2006, www.du-dau.net/publications.shtml.

[5] R. Freitas, P. A. S. Veloso, S. R. M. Veloso \& P. Viana (2008): On a graph calculus for algebras of relations. In W. Hodges \& R. de Queiroz, editors: LNAI, Series 5110, Springer-Verlag, Heiderberg, pp. 298-312, doi: $10.1007 / 978-3-540-69937-8$

[6] R. Freitas, P. A. S. Veloso, S. R. M. Veloso \& P. Viana (2009): Positive fork graph calculus. In S. Artemov, editor: LNCS, Series 5407, Springer-Verlag, New York, pp. 152-163, doi 10.1007/978-3-540-92687-0

[7] R. Freitas, P. A. S. Veloso, S. R. M. Veloso \& P. Viana (2010): A calculus for graphs with complement. In A. K. Goel, M. Jamnik \& N. H. Narayanan, editors: LNAI, Series 6170, pp. 84-98, Springer-Verlag, Berlin, doi:10.1007/978-3-540-92687-0.

[8] S . MacLane (1998): Categories for the Working Mathematician, second edition, Springer-Verlag, Berlin.

[9] A. Rensink (2004): Representing first-order logic using graphs, In H. Ehrig et al. editors: LNCS, Series 3256, pp. 319-335, Springer-Verlag, Heiderberg, doi 10.1007/978-3-540-30203-2.

[10] E. Robinson (2003): Proof nets for classical logic, J. Logic and Computat. volume(13) number(5), pp. 776-797, doi:10.1093/logcom/13.5.777.

[11] J. F. Sowa (2011): Existential graphs, doi:10.1515/semi.2011.060

[12] G. Takeuti (1975): Proof Theory, North-Holland, Amsterdam.

[13] P. A. S. Veloso and S. R. M. Veloso (2012): On Graph refutation for relational inclusions, In S. R. della Rocca and E. Pimentel, editors: EPTCS volume (81), pp. 47-66. doi $10.4204 / E P T C S .81 .4$ 